\title{
Neurturin regulates the lung-resident macrophage inflammatory response to viral infection
}

\author{
Emma Connolly ${ }^{1,2}$ (D, David J Morgan ${ }^{1,2}$, Miriam Franklin ${ }^{1,2}$, Angela Simpson ${ }^{3}$, Rajesh Shah ${ }^{4}$, Oliver J Brand $d^{1,2}$, \\ Christopher P Jagger ${ }^{1,2}$, Joshua Casulli, ${ }^{1,2}$, Karishma Mohamed ${ }^{1,2}$, Aleksander M Grabiec ${ }^{2}$ (D), Tracy Hussell ${ }^{1,2}$ (D)
}

\begin{abstract}
Lung-resident macrophages are crucial to the maintenance of health and in the defence against lower respiratory tract infections. Macrophages adapt to local environmental cues that drive their appropriate function; however, this is often dysregulated in many inflammatory lung pathologies. In mucosal tissues, neuroimmune interactions enable quick and efficient inflammatory responses to pathogenic threats. Although a number of factors that influence the antimicrobial response of lung macrophages are known, the role of neuronal factors is less well understood. Here, we show an intricate circuit involving the neurotrophic factor, neurturin (NRTN) on human lung macrophages that dampens pro-inflammatory cytokine release and modulates the type of matrix metalloproteinases produced in response to viral stimuli. This circuit involves type 1 interferon-induced up-regulation of RET that when combined with the glial cell line-derived neurotrophic factor (GDNF) receptor $\alpha 2$ (GFR $\alpha 2$ ) allows binding to epithelial-derived NRTN. Our research highlights a non-neuronal immunomodulatory role for NRTN and a novel process leading to a specific antimicrobial immune response by human lung-resident macrophages.
\end{abstract}

DOI 10.26508/Isa.202000780 | Received 15 May 2020 | Revised 15 September 2020 | Accepted 22 September 2020 | Published online 5 October 2020

\section{Introduction}

Lower respiratory tract infections and chronic respiratory diseases are within the top four causes of mortality globally (Barnes, 2019). Therefore, understanding the inflammatory cascades involved in the pathogenesis of these diseases is critical in developing new therapeutics and alleviating the clinical burden. Because of their location in the airways, lung-resident alveolar macrophages are in direct contact with the external environment and are at the first line of defence against infectious agents. For this reason, macrophage function needs to be tightly regulated to maintain homeostasis through tolerance to cellular debris and innocuous antigens, while still mounting an effective immune response against harmful pathogens and limiting bystander tissue damage (Hussell \& Bell, 2014). Upon host infection with a virus, lung macrophages produce a range of cytokines, including type I IFNs, IL-6, and IL-12, in response to TLR activation (Yan \& Chen, 2012; Goritzka et al, 2015). Type I IFNs, in turn, trigger the JAK-signal transducers and activators of transcription (STAT) pathway, which leads to the activation of a large number of interferon stimulated genes (Ivashkiv \& Donlin, 2014). These genes encode proteins that induce cell-intrinsic anti-viral defences, but also cytokines and chemokines that are critical in the immune response to clear the threat (Rauch et al, 2013; Rusinova et al, 2013). However, the specific interferon-stimulated genes induced in macrophages by a given pathogen or TLR receptor and how this directs the ensuing inflammatory cascade, especially in humans, is largely unknown.

Mucosal sites, including the lung, are highly innervated with peripheral nerves and growing evidence implicates neuro-immune interactions in health and disease in the gastrointestinal tract (Chesne et al, 2019). Conversely, how neuronal signals affect immune cell function in the lung is less well established. RET is a receptor tyrosine kinase that is activated by glial cell line-derived neurotrophic factor (GDNF) family receptors and their ligands (GFLs). GDNF binds to GDNF family receptor (GFR) $\alpha 1$, neurturin (NRTN) to GFR $\alpha 2$, artemin to GFR $\alpha$, and persephin to GFR $\alpha 4$ (Airaksinen \& Saarma, 2002). Ligand binding to the receptor promotes dimerization of RET and subsequent changes in biological processes such as differentiation, proliferation, and apoptosis (Lemmon \& Schlessinger, 2010), predominantly characterised in the nervous system. RET is essential for the development of the enteric nervous system (Schuchardt et al, 1994) and, through the formation of a GFR 23 /Artemin/RET signalling complex, governs the formation of enteric Peyer's patches (Veiga-Fernandes et al, 2007). However, the GDNF family also have non-neuronal immune-modulatory functions in the gastrointestinal tract. In this setting, TLR agonists or alarmins stimulate enteric glial cells to produce the ligands, GDNF, and NRTN (Ibiza et al, 2016). This in turn leads to the activation of RET-expressing

\footnotetext{
${ }^{1}$ The Lydia Becker Institute for Immunology and Inflammation, The University of Manchester, Manchester, UK ${ }^{2}$ Manchester Collaborative Centre for Inflammation Research, The University of Manchester, Manchester, UK ${ }^{3}$ Division of Infection, Immunity and Respiratory Medicine, Manchester Academic Health Sciences Centre, University of Manchester, Manchester, UK ${ }^{4}$ Department of Thoracic Surgery, University Hospital of South Manchester, Manchester, UK 
group 3 innate lymphoid cells (ILC3s) and subsequent production of IL-22 in a STAT3-dependent manner (Ibiza et al, 2016). IL-22 then acts on gut epithelial cells to drive antimicrobial responses, therefore implicating the GDNF family in promoting host defence against infection (Ibiza et al, 2016).

Evidence also implicates the GDNF family in other diverse aspects of the immune system. NRTN exhibits anti-inflammatory properties by inhibiting the secretion of IL- 6 and TNF $\alpha$ from LPSstimulated human PBMCs (Vargas-Leal et al, 2005) and dampens the inflammatory response to allergens in a mouse model of asthma (Mauffray et al, 2015). Within the bone marrow, RET signalling promotes haematopoietic stem cell survival and function (Fonseca-Pereira et al, 2014) and regulates their daily migration into the circulation (Garcia-Garcia et al, 2019). Meanwhile GFR $\alpha 2$ has been defined as a marker for the human intermediate monocyte subset (Wong et al, 2011) and B cell progenitors (Jensen et al, 2018). Therefore, this accumulating data clearly shows that GDNF family members play significant roles in shaping immune responses.

We hypothesised that receptors classically attributed to neuronal cells would be expressed by lung macrophages and drive their function. We searched for neuronal receptors on human lungresident macrophages and found a specific sequence of steps leading to formation of a GFR $\alpha 2$-RET-NRTN complex that was amplified in lung macrophages from chronic smokers and tumour tissue. We determined that viral infection, or mimics thereof, specifically enhanced the production of the GFR $\alpha 2$ ligand, NRTN, from lung epithelium, whereas type I IFNs induced expression of the signalling receptor RET in lung macrophages. RET activation led to a reduction in pro-inflammatory cytokine release and a switch in the type of matrix metalloproteinases (MMPs) produced from macrophages. This highly specific outcome following the precise development of a multi-component receptor highlights an important, non-neuronal role for GFR $\alpha 2$ in directing macrophage function to promote host defence.

\section{Results}

\section{Human lung macrophages constitutively express GFR $\alpha 2$ and the} signalling co-receptor RET is induced by TLR activation

Though neuronal factors have been predominantly characterised in the nervous system, we observed high GFR 22 expression under conditions of GM-CSF, compared with M-CSF, differentiation of murine BMDMs by $\mathrm{RT}^{2}$ profiler array (Fig S1A and B) and confirmed this by quantitative (q)PCR (Fig S1C and D). GMCSF plays a significant role in lung immune homeostasis and is critical in the development of alveolar macrophages (Schneider et al, 2014). Consistent with in vitro data, GFR $\alpha 2$ was highly expressed on mouse (Fig S1E) and human lung macrophages, compared with other members of the GDNF family, at the mRNA level (Fig 1A). GFR $\alpha 2$ was also expressed on human peripheral blood monocytes and human monocytederived macrophages (MDMs) (Fig 1B). On the other hand, the co-receptor, RET, could not be detected in monocytes, human MDMs or human lung macrophages (MDS) at steady state (Fig 1A and B). GFR $\alpha 2$ and RET expression was further confirmed at the protein level, with GFR $\alpha 2$ expression observed in human lung macrophages and human MDMs (Fig $1 C$ and D), whereas the coreceptor RET was only detected in PMA-treated THP-1 macrophages (Fig 1D). To determine the trigger for macrophage expression of RET; human MDMs were stimulated with Th1/Th2 cytokines and TLR agonists. Cytokines associated with polarising macrophages had little effect on RET expression (Fig 1E); however, RET mRNA expression was significantly induced by the TLR3 agonist, polyl:C, and to a lesser extent by the TLR4 and TLR7/8 agonists, LPS and R848, respectively (Fig $1 \mathrm{E}$ ). Therefore, although macrophages constitutively express GFR $\alpha 2$, the signalling component, RET, is induced by stimuli associated with viral infection.

\section{Lung epithelial cells express the GDNF family ligand NRTN}

We next determined that one possible source of the GFR $\alpha 2$ ligand was airway epithelial cells, where NRTN was detected under basal conditions at the MRNA (Fig 1F) and protein (Fig 1G) level in the A549 cell line. This was confirmed in the bronchial epithelial cell line BEAS-2B (Fig S2A). Interestingly, the dominant GFRa receptor in epithelial cells is GFR 1 (Figs $1 \mathrm{~F}$ and S2B). Enhanced production of NRTN was observed in A549 cells after stimulation with polyl:C and LPS (Fig 1G). Furthermore, increased NRTN was detected in the BAL fluid of influenza infected mice at time points associated with peak inflammation (Fig S2C). This data further supports a role for the GFRa2-RET-NRTN complex in host defence by lung macrophages. Moreover, GFR $\alpha 2$ expression by monocytes and macrophages suggests that this is not tissue specific or associated with a particular monocyte/macrophage lineage.

\section{Macrophage RET expression is indirectly induced by TLR agonists via type I IFNs}

The TLR3 receptor agonist polyl:C triggers a downstream signalling cascade involving TANK-binding kinase 1 (TBK1) that induces the production of type I IFNs (Clark et al, 2011). In human MDMs, polyl:C enhanced IFN $\alpha$ and IFN $\beta$ mRNA (Fig S3A and $\mathrm{B}$, respectively). However, in human lung macrophages, polyl:C significantly upregulated the protein release (Fig $2 A$ ) and mRNA of IFN $\beta$ (Fig 2B), but not IFNa (Fig S3C). Blockade of TBK1 activation with BX795 abolished polyl:C-induced up-regulation of IFN $\beta$ (Fig 2A and B) and RET mRNA by human lung macrophages (Fig 2C). To determine whether RET is induced directly or indirectly by TLR3 activation, human lung macrophages (Fig 2D), human peripheral blood monocytes (Fig 2E) and human MDMs (Fig 2F) were stimulated with IFNs (IFN $\alpha$, IFN $\beta$, IFN $\gamma$, and IFN $\lambda$ ). RET expression was up-regulated by IFN $\beta$ in all three cell types at the mRNA level (Fig 2D-F). Furthermore, a slight increase in GFR $\alpha 2$ expression was observed in human lung macrophages by IFNy (Fig S3D). The mRNA for the most common RET isoforms, RET 9 and RET 51, were both up-regulated by IFN $\beta$, and to a lesser extent IFN $\alpha$ stimulation, in human lung macrophages (Fig S3E). This RET up-regulation was confirmed at the protein level in human MDMs using different concentrations of IFN $\beta$ (Fig $2 \mathrm{G}$ and $\mathrm{H}$ ). GFR 2 2 protein, however, remained unchanged (Fig 2l). Although THP-1 monocytes and PMA-treated THP-1 macrophages expressed RET constitutively (Figs S3F and 1D, respectively), 
A

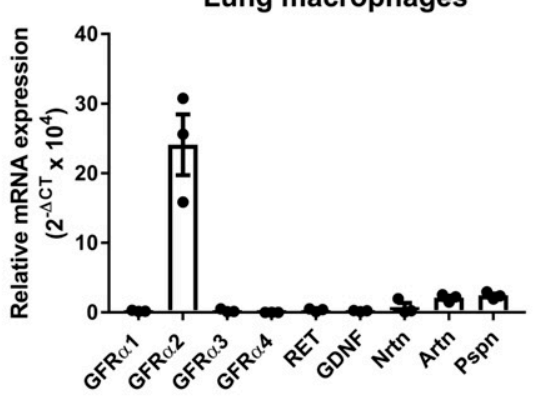

C

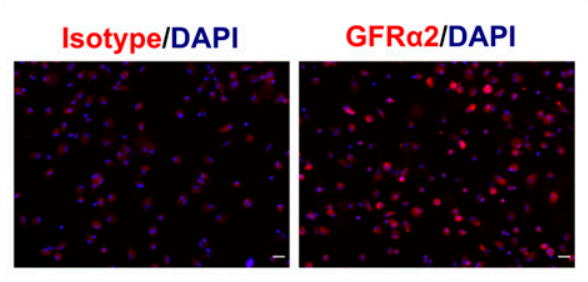

$\mathbf{E}$

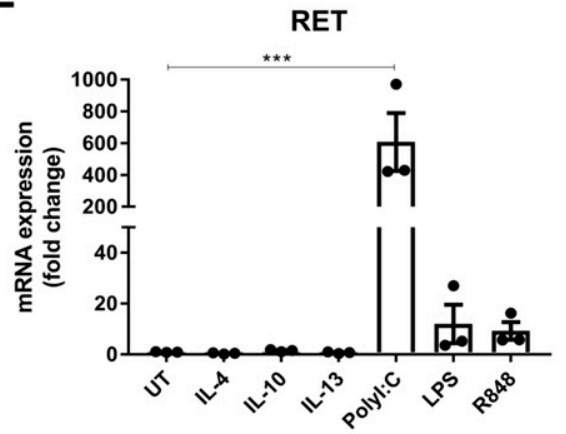

$\mathbf{G}$

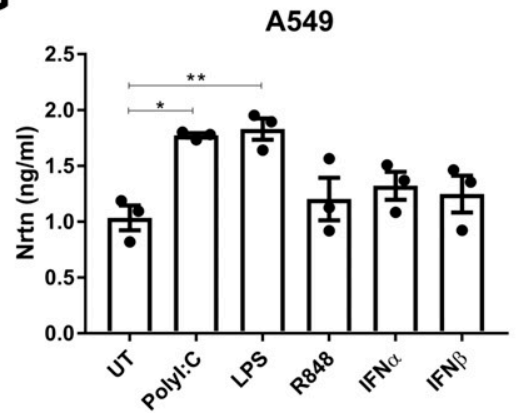

B

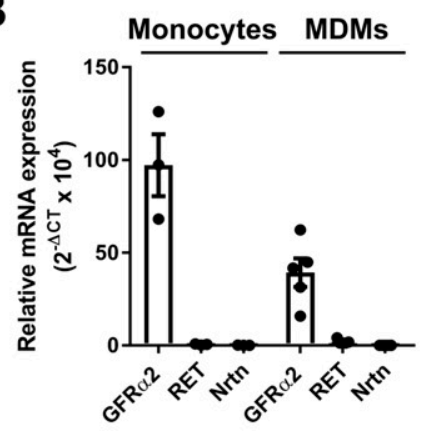

D

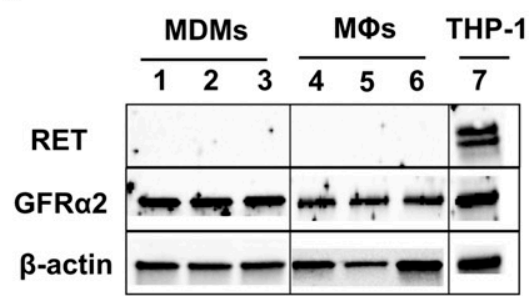

$\mathbf{F}$

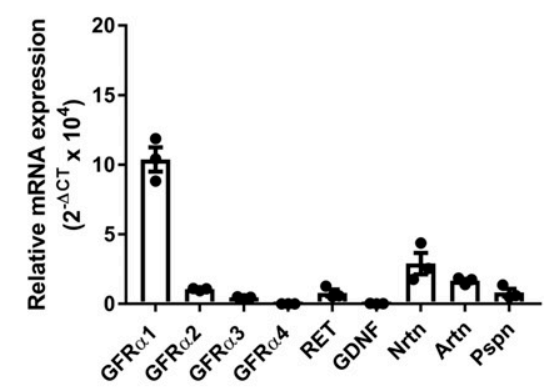

Figure 1. Human lung macrophages express GFR $\alpha 2$ and induce RET expression after TLR activation, whereas lung epithelial cells express the ligand NRTN.

(A) Relative mRNA expression $\left(2^{-\triangle C T} \times 10^{4}\right)$ of GDNF family receptors and ligands in human lung macrophages $(n=3)$. (B) Relative mRNA expression of GFR $\alpha 2, R E T$, and NRTN in peripheral blood monocytes $(n=3)$ or MDMs $(n=6)$ from non-matched donors. (c) Representative images of GFR $\alpha 2$ expression in human lung macrophages by immunofluorescence (GFR $\alpha 2$ or isotype control [red] DAPI [blue]). Scale bar $=20 \mu \mathrm{M}$. (D) Representative Western blot of GFR $\alpha 2$ and RET protein expression in MDMs (lanes $1-3)(n=3)$, human lung macrophages (MФs) (lanes $4-6)(n=3)$ and PMAtreated THP-1 macrophage positive control (lane 7); $\beta$-actin housekeeping control. (E) mRNA expression of RET in MDMs after stimulation with IL-4, IL-10, IL-13 (all 20 $\mathrm{ng} / \mathrm{ml}$ ), polyl:C (10 $\mu \mathrm{g} / \mathrm{ml}), \mathrm{LPS}$, or R848 (both $100 \mathrm{ng} / \mathrm{ml}$ ) for $24 \mathrm{~h}(\mathrm{n}=3)$ expressed as a fold change over the average expression of untreated (UT) cells. (F) Relative mRNA expression $\left(2^{-\Delta C T} \times 10^{4}\right)$ of GDNF family receptors and ligands in A549 cells $(n=3)$. (G) ELISA analysis of NRTN in A549 cells stimulated with polyl:C $(10 \mu \mathrm{g} / \mathrm{ml})$, LPS, R848 (both $100 \mathrm{ng} / \mathrm{ml}$ ), IFN $\alpha$ or IFN $\beta$ (both 20 $\mathrm{ng} / \mathrm{ml})$ for $24 \mathrm{~h}(\mathrm{n}=3)$. Data information: Data are shown as mean \pm SEM from three to six independent experiments. $(\mathbf{E}, \mathbf{G}){ }^{*} P<0.05,{ }^{* \star} P<0.01$, ${ }^{* * *} P<0.001$; one-way ANOVA with Tukey's post hoc test with multiple comparisons (E, G). Source data are available for this figure.
IFN $\beta$ further enhanced RET protein in PMA-treated THP-1 macrophages (Fig 2J).

\section{NRTN up-regulates MMP2 production by human lung macrophages}

To determine the function of NRTN on human lung macrophages, we ran a GPCR array analysis for genes related to macrophage function. In the case for macrophages from this donor, NRTN alone had mild effects on macrophages, including the up-regulation of neuropeptide $Y$ receptor type 2 (NPY2R) but down-regulation of NPY1R (Fig S4A). This mild effect of NRTN likely reflects that RET expression has not been induced and so we next examined the effect of NRTN on IFN $\beta$-stimulated human lung macrophages. IFN $\beta$ alone increased mRNA for the granulocyte chemoattractant, CXCL8 and the lymphocyte chemoattractant, CXCL9 (Fig S4B). However, IFN $\beta$ stimulation of human lung macrophages with the addition of NRTN enhanced MMP2 mRNA and down-regulated IL-6, IFNy, MAPK, MMP9, and IL-12A compared with IFN $\beta$ alone (Fig S4C). Gain-offunction mutations in RET lead to the development of specific 
A

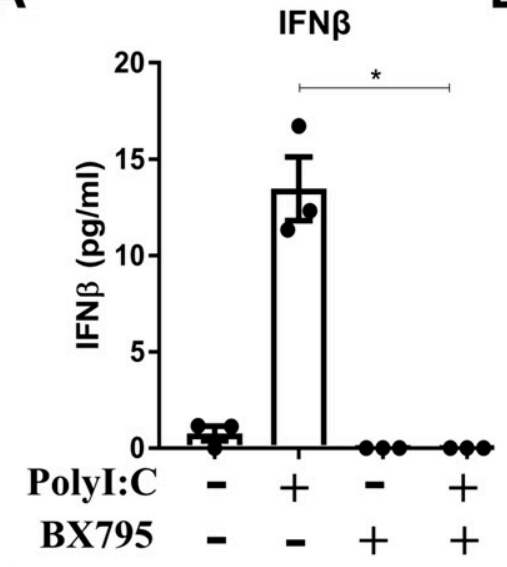

D

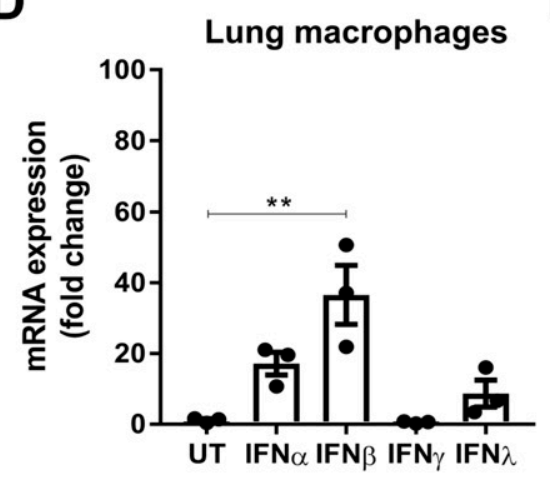

G

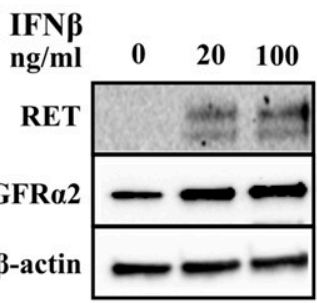

H
B

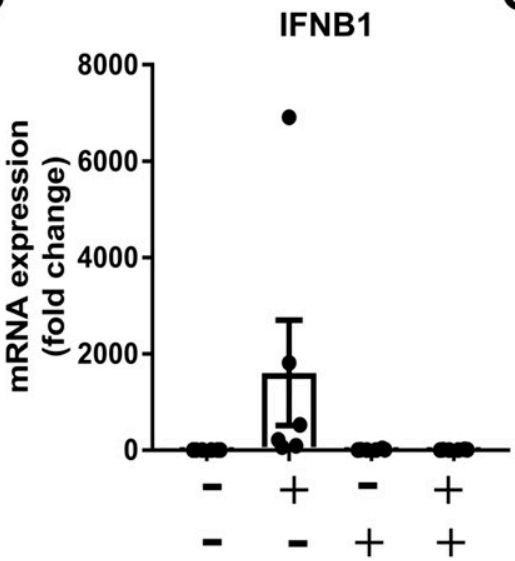

E

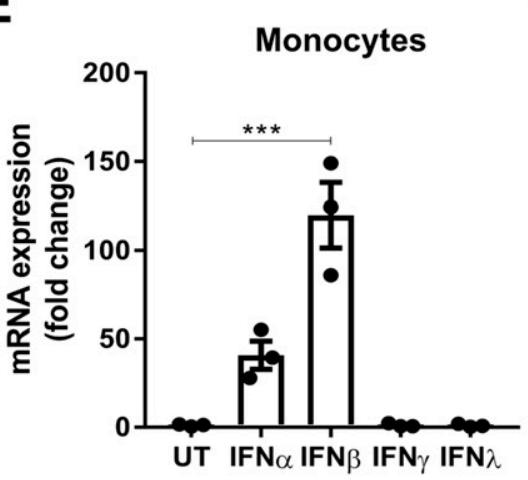

I

C

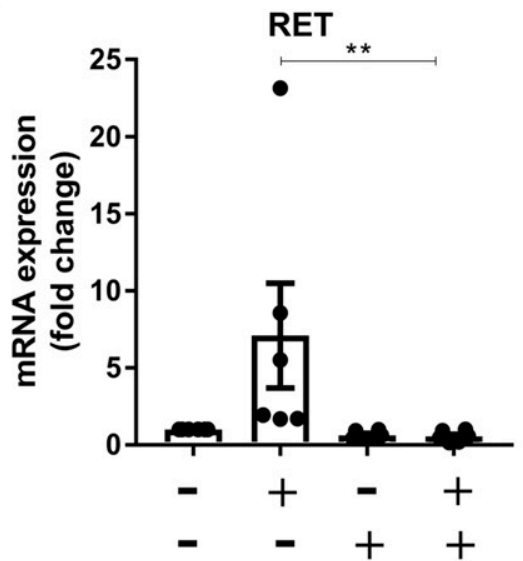

F
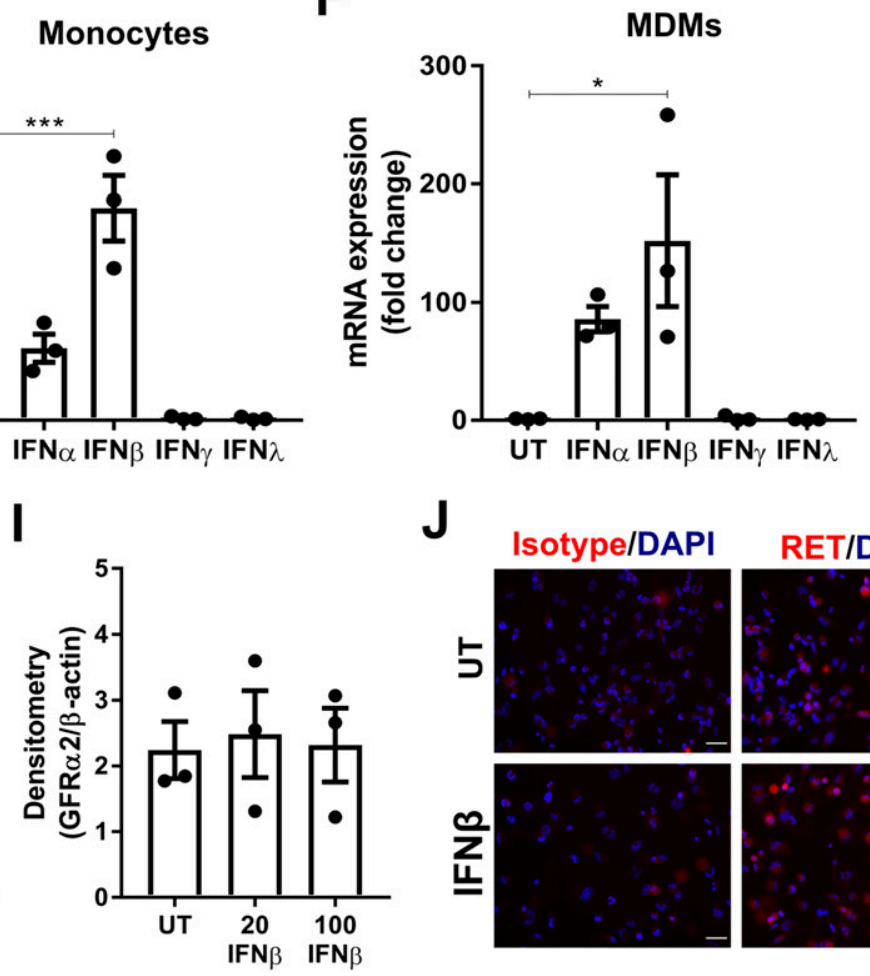

J
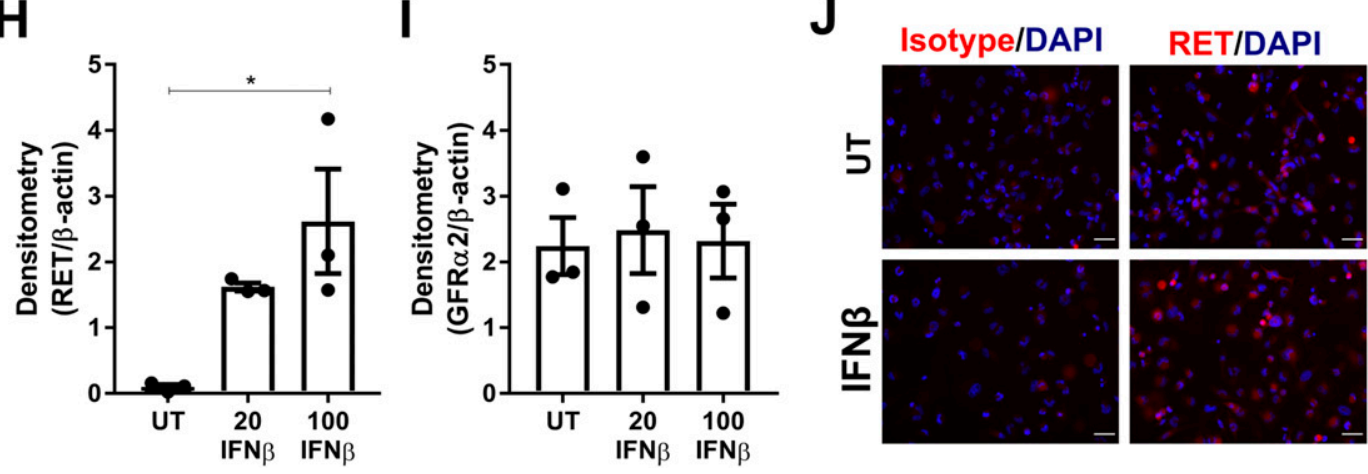

Figure 2. Macrophage RET expression is indirectly stimulated by TLR agonists via type I IFNs.

$(A, B, C)$ ELISA analysis of IFN $\beta$ release $(n=3)(A)$ and mRNA expression of IFN $\beta(B)$ or RET $(C)(n=6)$ in human lung macrophages stimulated with polyl:C $(10 \mu \mathrm{g} / \mathrm{ml}) \pm$ BX795 (5 $\mu \mathrm{g} / \mathrm{ml}$ ) for $24 \mathrm{~h}$. (D, E, F) RET mRNA expression in human lung macrophages (D), human peripheral blood monocytes (E), and human MDMs (F) stimulated with IFN $\alpha$, IFN $\beta$, IFNy, or IFN (all at $20 \mathrm{ng} / \mathrm{ml}$ ) for $24 \mathrm{~h}(\mathrm{n}=3)$. (G, H, I) Representative Western blot (untreated [lane 1], $20 \mathrm{ng} / \mathrm{ml}$ IFN $\beta$ [lane 2], $100 \mathrm{ng} / \mathrm{ml}$ IFN $\beta$ [lane 3]) (G) and densitometry analysis of RET (H) and GFR $\alpha 2$ (I) protein expression relative to $\beta$-actin in human MDMs stimulated with $20 \mathrm{ng} / \mathrm{ml}$ or $100 \mathrm{ng} / \mathrm{ml}$ of IFN $\beta$ for $24 \mathrm{~h}$ ( $\mathrm{n}=3$ ). (J) Representative images of RET expression in untreated or IFN $\beta$-treated PMA-treated THP-1 macrophages (top panels; untreated [UT], bottom panels; IFN $\beta$-treated [20 ng/ $\mathrm{ml}$ ], RET [red] DAPI [blue]). Scale bar $=40 \mu \mathrm{M}$. Data information: Data are shown as mean $\pm \mathrm{SEM}$ from three to six independent experiments. $(\mathbf{A}, \mathbf{C}, \mathbf{D}, \mathbf{E}, \mathbf{F}, \mathbf{H}) * P<0.05,{ }^{*} \mathrm{P}<$ $0.01{ }^{* * *} P<0.001$; one-way ANOVA with Tukey's post hoc test with multiple comparisons (A, D, E, F, H); Kruskal-Wallis test with Dunn's multiple comparisons test (C). Source data are available for this figure.

human cancers and have been associated with the regulation of MMPS, including MMP2 and MMP9, which are thought to drive metastasis (Kato et al, 1998; Asai et al, 1999). To validate the effect of NRTN on MMP2 production, human lung macrophages were stimulated with polyl:C or IFN $\beta$, with or without NRTN. Polyl:C-stimulated human lung macrophages, with the addition of NRTN, significantly enhanced the production of MMP2 ( 140 kD, homodimer) (Fig 3A and $B)$. In contrast to the changes in MMP2 at the mRNA level, NRTN did not enhance MMP2 production in IFN $\beta$-stimulated human lung macrophages (Fig 3B). The expression of MMP9 was also analysed as this MMP belongs to the same group as MMP2, the gelatinases; however, MMP9 ( 92 kD) was unchanged by NRTN stimulation (Fig 
A

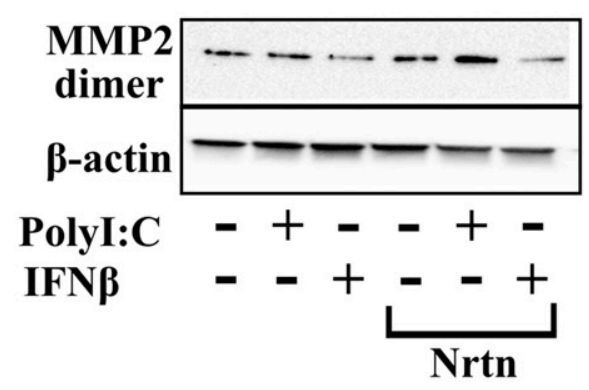

C

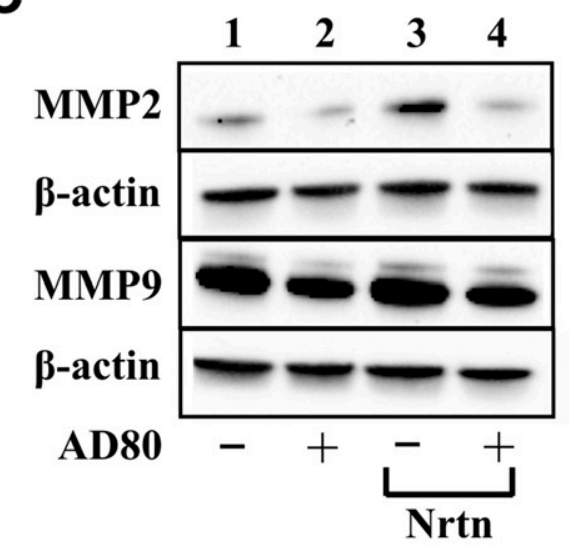

$\mathbf{F}$

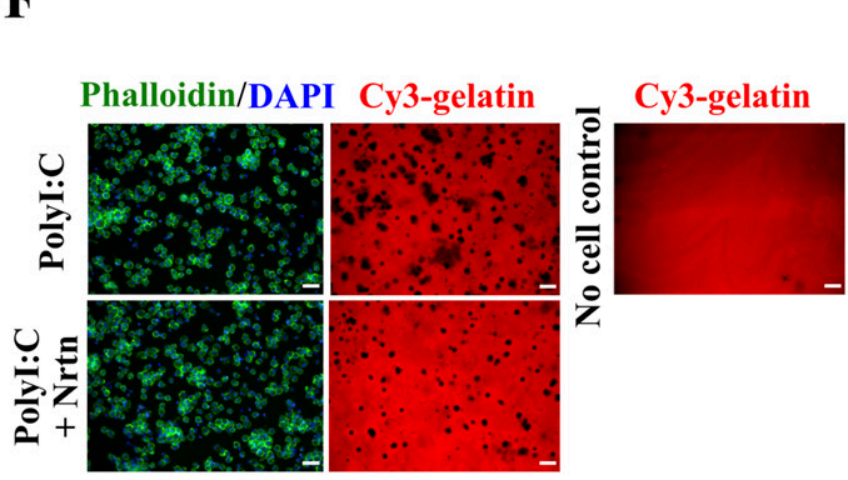

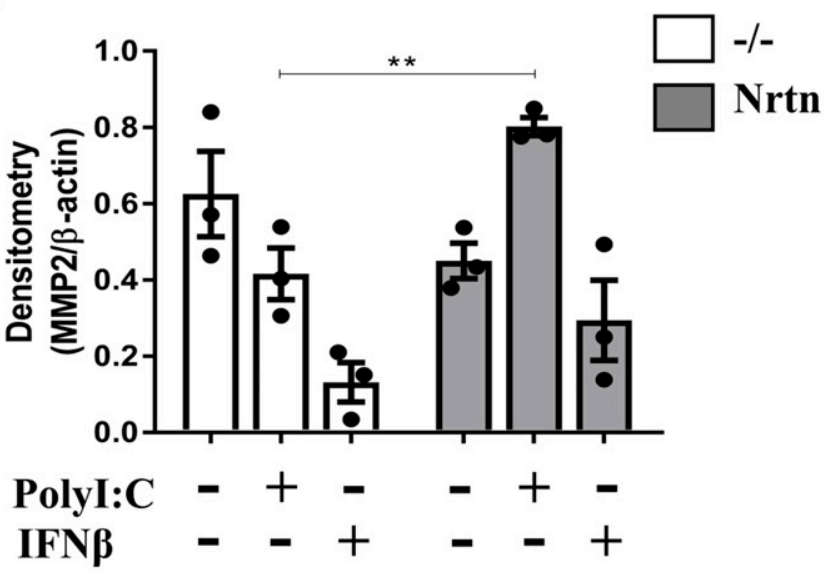

$\mathbf{E}$

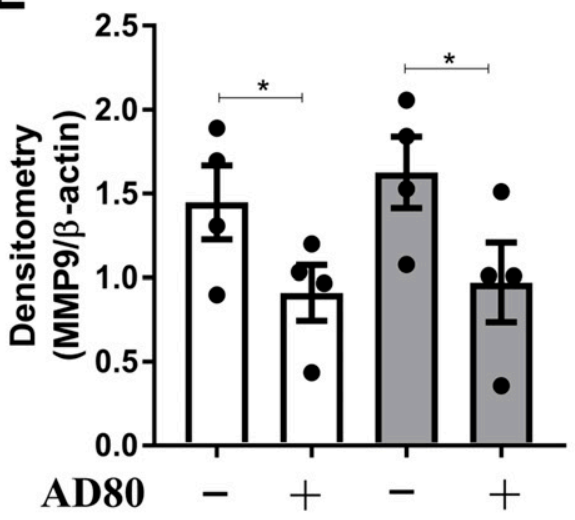

\section{G}

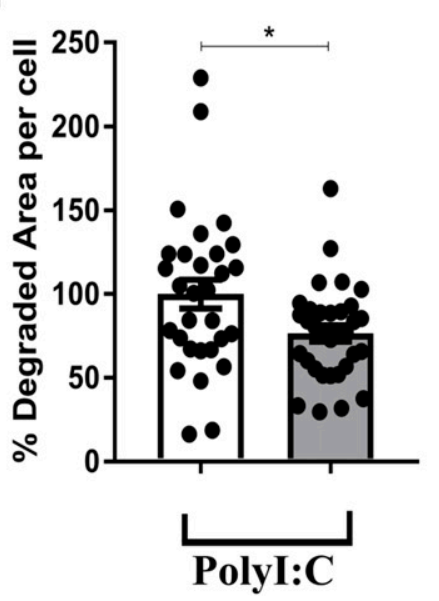

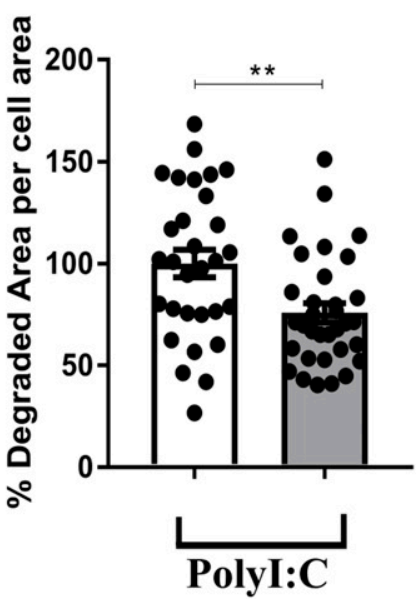

Figure 3. NRTN promotes MMP2 and MMP9 production from macrophages.

(A, B) Representative Western blot (A) and densitometry analysis (B) of MMP2 in human lung macrophages treated with polyl:C (10 $\mu \mathrm{gg} / \mathrm{ml})$ or IFN $\beta$ (20 ng/ml) \pm NRTN (100 $\mathrm{ng} / \mathrm{ml}$ ) for $24 \mathrm{~h}(\mathrm{n}=3)$. (C, D, E) Representative Western blot $(C)$ and densitometry analysis of MMP2 (D) or MMP9 (E) protein expression in PMA-treated THP-1 macrophages stimulated with AD80 $(0.5 \mu \mathrm{M}) \pm$ NRTN $(100 \mathrm{ng} / \mathrm{ml})$ for $24 \mathrm{~h}(\mathrm{n}=4)$. Densitometry analysis of MMP2 and MMP9 is expressed relative to $\beta$-actin. $(\mathbf{F}, \mathbf{G})$ Representative image $(\mathrm{F})$ and quantification per cell and per cell area (G) of gelatin degradation by human lung macrophages stimulated with polyl:C $(10 \mu \mathrm{g} / \mathrm{ml}) \pm \mathrm{NRTN}(100 \mathrm{ng} / \mathrm{ml})$ for $24 \mathrm{~h}(\mathrm{n}=3)$. Each dot on the graph represents a field of view, minimum seven fields of view per donor. Scale bar $=50 \mu \mathrm{M}$. Data information: Data are shown as mean \pm SEM from three or four independent experiments. (B, D, E, G) ${ }^{\star} P<0.05,{ }^{*} P<0.01$, ${ }^{* *} P<0.001$; Student's paired two-tailed $t$ test $(\mathrm{B}, \mathrm{D}, \mathrm{E}, \mathrm{G})$.

Source data are available for this figure. 

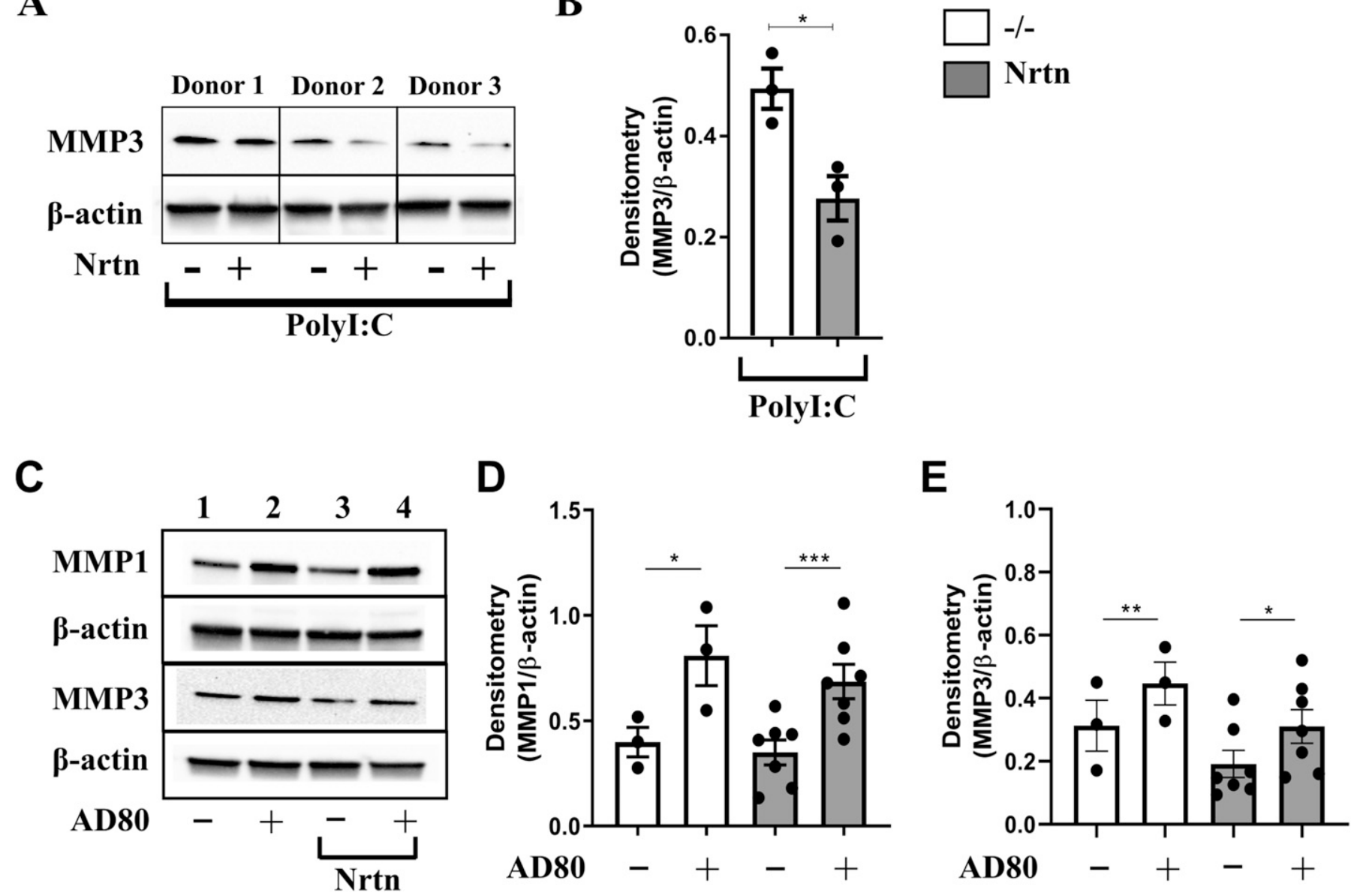

Figure 4. NRTN reduces MMP1 and MMP3 production from macrophages.

(A, B) Representative Western blot (A) and densitometry analysis of MMP3 (B) in human lung macrophages stimulated with polyl:C (10 $\mu \mathrm{g} / \mathrm{ml}) \pm \mathrm{NRTN}(100 \mathrm{ng} / \mathrm{ml})$ for $24 \mathrm{~h}(\mathrm{n}=3)$. (C, D, E) Representative Western blot (C) and densitometry analysis of MMP1 (D) or MMP3 (E) protein expression in PMA-treated THP-1 macrophages stimulated with AD80 (0.5 $\mu$ M) \pm NRTN (100 ng/ $\mathrm{ml}$ ) for $24 \mathrm{~h}(\mathrm{n}=3-7)$. Densitometry analysis of MMP1 and MMP3 is expressed relative to $\beta$-actin. Data information: Data are shown as mean \pm SEM from three independent experiments. (B, D, E) ${ }^{\star} P<0.05$; Student's paired two-tailed $t$ test $(B, D, E)$.

Source data are available for this figure.

S4D and E). Interestingly, IFN $\beta$ significantly reduced MMP9 protein release from lung macrophages (Fig S4F), although this was not observed at the mRNA level (Fig S4B).

To determine whether inhibition of RET leads to the down-regulation of MMP2 production in macrophages, the RET inhibitor, AD80, was used in PMA-treated THP-1 macrophages. A reduction in MMP2 ( 72 kD) and MMP9 ( 92 kD) production following treatment with AD80 was observed in both the presence and absence of NRTN (Fig 3C-E). To investigate whether the changes in MMP2 production induced by NRTN in polyl:Cstimulated macrophages had a functional effect on MMP2 activity we performed a gelatin degradation assay. A reduction in MMP activity from polyl:C and NRTN stimulated human lung macrophages was observed as measured by their reduced ability to degrade gelatin when analysed per number of cells or by cell area, compared with polyl:C alone (Fig 3F and G). This reduction in gelatin degradation did not correlate with the increase in MMP2 production observed and suggests that NRTN via RET ligation may either negatively affect MMP2 activity or regulate the production of other MMPs that can degrade gelatin.

\section{NRTN down-regulates MMP1 and MMP3 production by macrophages}

To determine whether NRTN can regulate the production of other types of MMPs by human lung macrophages, the production of the interstitial collagenase, MMP1, and the stromelysin, MMP3, was analysed. The production of MMP1 and MMP3 has been previously linked to RET activation (Mesa et al, 2006; Kang et al, 2009) and gelatin is a known substrate for both of these MMPs. Polyl:C-stimulated human lung macrophages, with the addition of NRTN, down-regulated the production of MMP3 ( 20 kD form) compared with polyl:C alone (Fig 4A and B). MMP1 was not expressed by human lung macrophages (data not shown). Conversely RET inhibition by AD80, in the presence or absence of NRTN, in PMA-treated THP-1 macrophages increased the expression of MMP1 ( 53 $\mathrm{kD})$ and MMP3 ( $\sim 54 \mathrm{kD})$ (Fig 4C-E). Overall, these data show that RET activation via Gfro2 and NRTN decreases the production of MMP3 and promotes MMP2 in primary human lung macrophages but MMP activity may also be affected. Our data suggest that RET could switch the 
A

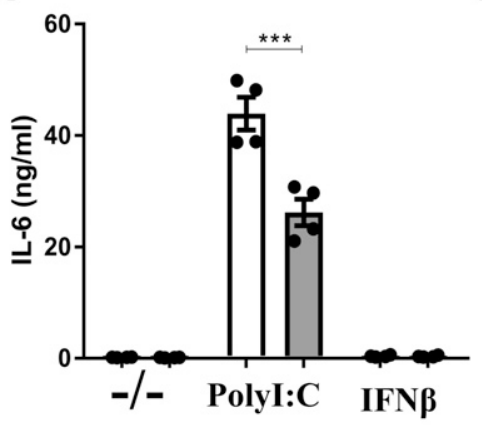

C

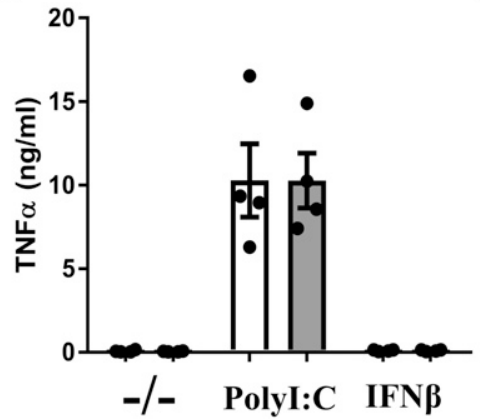

B

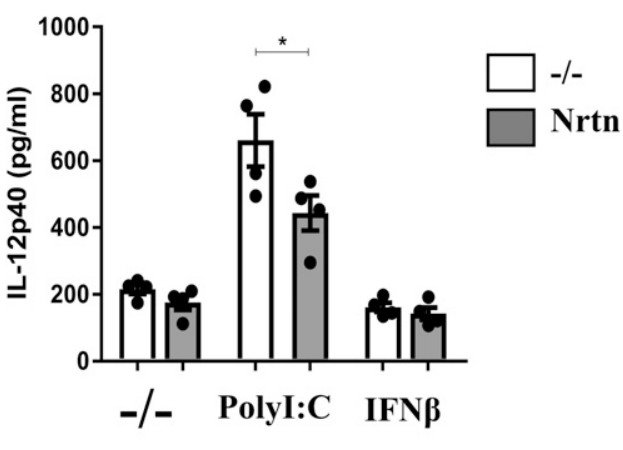

Figure 5. NRTN dampens the release of proinflammatory cytokines from human lung macrophages.

(A, B, C, D) ELISA analysis of IL-6 (A), IL-12p40 (B), TNFa (C) and IL-10 (D) release from human lung macrophages stimulated with polyl:C $(10 \mu \mathrm{g} / \mathrm{ml})$ or IFN $\beta(20 \mathrm{ng} / \mathrm{ml}) \pm N R T N(100 \mathrm{ng} / \mathrm{ml})$ for $24 \mathrm{~h}(\mathrm{n}=4)$. Data information: Data are shown as mean \pm SEM from four independent experiments. (A, B) ${ }^{*} P<0.05,{ }^{* * *} P<$ 0.001; one-way ANOVA with Tukey's post hoc test with multiple comparisons (A, B).

Source data are available for this figure.
D

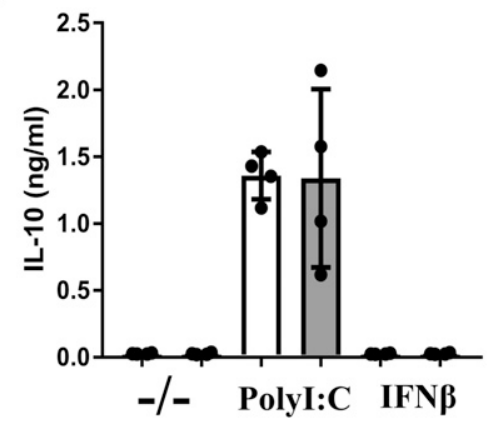

production of MMPs produced by macrophages depending on the demands of the tissue at that time.

\section{NRTN dampens the release of pro-inflammatory cytokines from human lung macrophages}

The GDNF family is a member of the wider TGF $\beta$ superfamily and as such have been hypothesised to have anti-inflammatory properties. In our system, NRTN significantly decreased the release of IL-6 (Fig 5A) and IL-12p40 (Fig 5B), but not TNF $\alpha$ (Fig 5C) or IL-10 (Fig 5D), from polyl:C-stimulated human lung macrophages. This suggests that NRTN may prevent excessive inflammation and limit further tissue damage during a viral infection. The data also corroborate an antiinflammatory role for the GDNF family.

\section{GDNF family expression is enhanced in macrophages from the lungs of chronic smokers and tumour tissue}

MMPs are implicated in a range of chronic airway diseases, such as asthma, chronic obstructive pulmonary disease (COPD) (Hendrix \& Kheradmand, 2017), and cancer metastases (Kessenbrock et al, 2010). GFR 2 2, RET, and MMP2 mRNA expression was analysed in lung macrophages from patients with COPD compared with patients with no underlying respiratory disease (Fig $6 \mathrm{~A}-\mathrm{C}$ ). No significant differences could be identified. However, if patients were categorised based on their smoking status, a significant increase in GFR 22 and MMP2 mRNA was detected in lung macrophages from current smokers compared with non-smokers, regardless of disease status (Fig 6D-F). A recent genome-wide association study study found that RET expression is linked to the number of cigarettes smoked per day (Matoba et al, 2019); however, we did not see enhanced RET mRNA expression in lung macrophages from smokers compared with non-smokers in our smaller study group (Fig 6E). GFR $\alpha 2$ and RET mRNA was also compared between macrophages isolated from lung tumours and surrounding healthy margin tissue. Although no difference was detected in GFRa2 mRNA (Fig 6G), RET mRNA was increased in tumour compared with margin macrophages (Fig $6 \mathrm{H}$ ). These data suggest that the GDNF family may be important factors to investigate further in the context of smoking/COPD and lung cancer, with regard to their effect on MMP production.

\section{Discussion}

Our data demonstrate that NRTN drives a functional switch in human lung-resident macrophages that inhibits inflammatory cytokine production and controls the expression of MMPs (Fig 7). That Gfra2 was expressed on monocytes and macrophages irrespective of their stage of differentiation, tissue location, or subtype, which suggests a fundamental role in macrophage biology. Regulation of MMP production via this pathway relies on viral triggers to promote NRTN production from epithelial cells and type I IFN to upregulate the signalling adapter RET in macrophages. Collectively, the data imply an important role for this multi-component receptor in airway host defence.

Accumulating evidence describes a role for the GDNF family in shaping an antimicrobial immune response. Intestinal ILC3S are critical regulators of host defence (Artis \& Spits, 2015) that constitutively express RET and respond to neurotrophic factors secreted by glial cells (Ibiza et al, 2016). In this case, the outcome is IL22 release that in turn initiates repair genes in epithelial cells and promotes host defence. The induction of RET by type I IFNs that we 
A

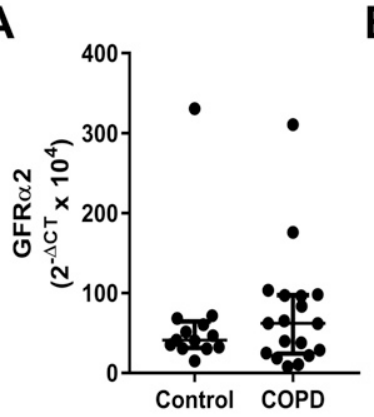

B
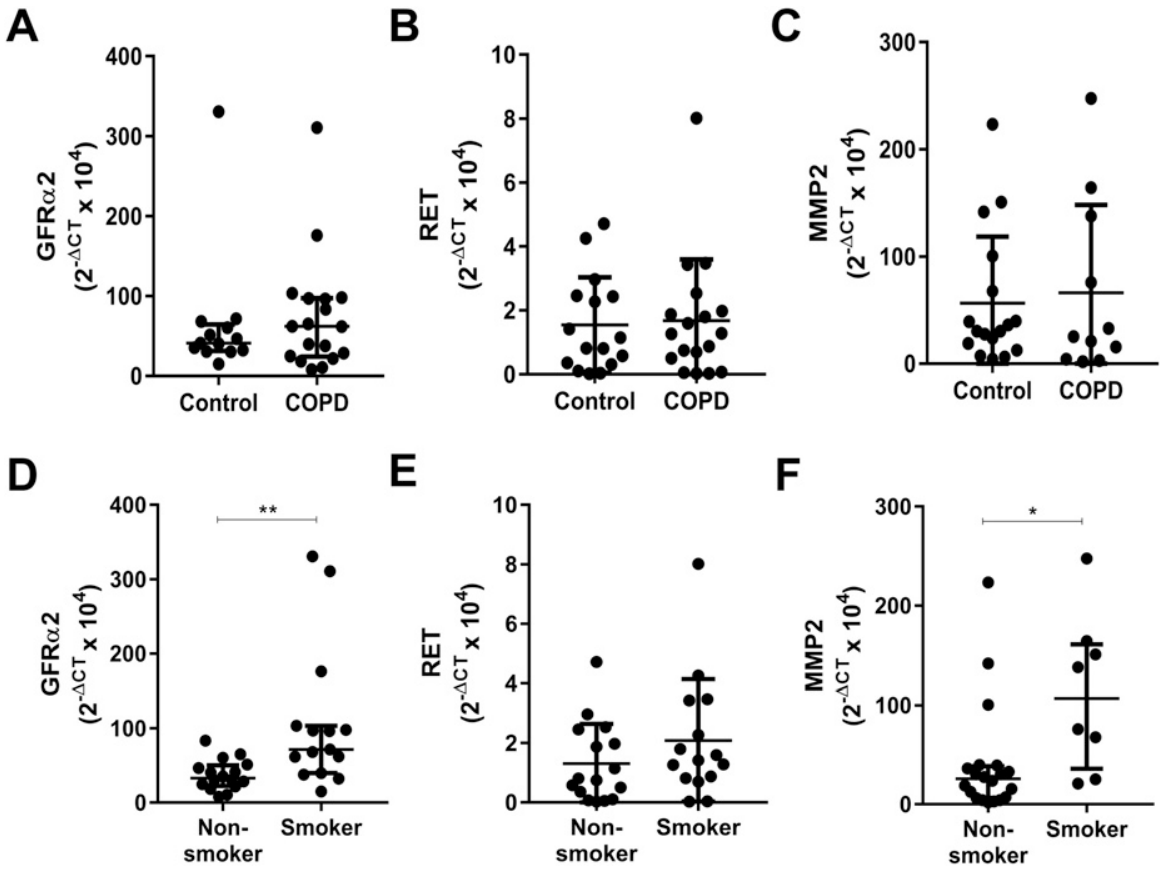

E

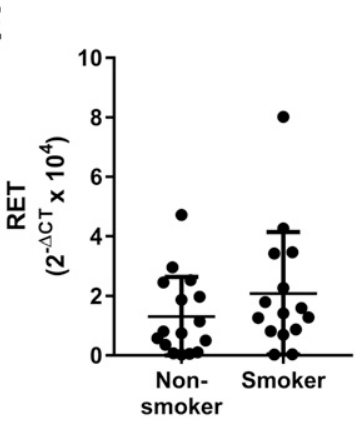

$\mathbf{F}$

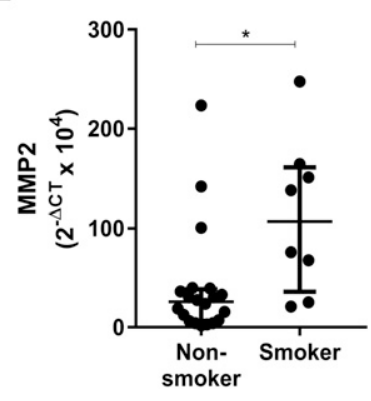

Figure 6. GDNF family expression is enhanced in macrophages from the lungs of chronic smokers and lung tumour tissue.

(A, B, C) Relative GFR 2 (A), RET (B), and MMP2 (C) mRNA expression $\left(2^{-\Delta C T} \times 10^{4}\right)$ in macrophages isolated from the lungs of patients categorised as "controls" (n = 16) or chronic obstructive pulmonary disease (GFR 2 and RET, $n=18 ; M M P 2, n=11)$. (D, E, F) Relative GFR $\alpha 2$ (D), RET (E), and MMP2 (F) mRNA expression in macrophages isolated from the lungs of patients categorised as non-smokers $(n=18)$ or smokers (GFR 2 and RET, $\mathrm{n}=16 ; \mathrm{MMP2}, \mathrm{n}=8)$. $(\mathbf{G}, \mathbf{H})$ Relative mRNA expression $\left(2^{-\triangle C T} \times 10^{4}\right)$ of GFRa2 $(G)$ and RET $(H)$ in macrophages isolated from lung tumour tissue and matching healthy margin tissue $(n=4)$. (A, B, C, D, $\mathbf{E}, \mathbf{F})$ Data information: Data are shown as median \pm interquartile range (A, B, C, D, E, F). (D, F, H) *P< 0.05 , ${ }^{* *} P<0.01$; Mann-Whitney $\cup$ test $(D, F)$, Student's paired two-tailed $t$ test $(\mathrm{H})$.

Source data are available for this figure.
G

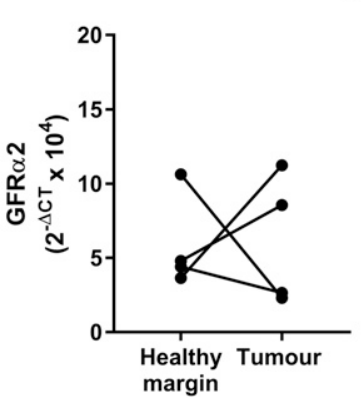

H

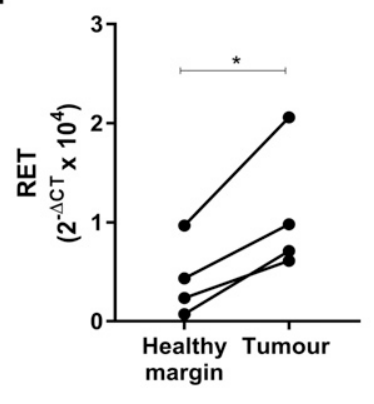

observe in macrophages implicates the GDNF family in mediating host defence in the respiratory tract. We show that RET activation in human lung macrophages by NRTN alters the production of MMPS by enhancing MMP2 and reducing MMP3 production. We also observe that RET inhibition in THP-1 macrophages decreases the production of MMP2 and MMP9 and enhances the production of MMP1 and MMP3. RET activation may therefore provide a critical hub for the control of macrophage MMP production. The MMPs are a family of zinc-dependent endopeptidases and have various important functions in infection, disease, repair and lung development (Beeh et al, 2003; Belvisi \& Bottomley, 2003; Hendrix \& Kheradmand, 2017). MMPs are expressed at relatively low levels at homeostasis but are up-regulated during inflammation and their production must be tightly controlled (Loffek et al, 2011). One important role of MMPs is the degradation of the ECM and interestingly in NRTN knockout mice, enhanced collagen deposition is evident around the airways, although the mechanism is unknown (Mauffray et al, 2015). Our data suggest that this may be due to the effect of NRTN on lung macrophage MMP production.

MMPs have fundamental roles in immune cell trafficking to sites of infection and this is achieved through cleaving transmembrane- and matrix-embedded proteins, including chemokines, and regulating the activity of cytokines (Sternlicht \& Werb, 2001; Overall, 2002). The MMPs we studied have been implicated in the activation of the pro-inflammatory cytokines TNF $\alpha$ and IL- $\beta$ and the antiinflammatory TGFß (Gearing et al, 1994; Ito et al, 1996; Schönbeck et al, 1998; Dallas et al, 2002; Karsdal et al, 2002; Maeda et al, 2002). ProTNF $\alpha$ is cleaved to its active form by MMP1, MMP2, MMP3 and MMP 9 (Gearing et al, 1994), whereas MMP2, MMP3, and MMP9 cleave latent TGF $\beta$-binding protein-1 to release TGF $\beta$ (Dallas et al, 2002; Maeda et al, 2002) and may also directly activate the latent form of TGF $\beta$ (Karsdal et al, 2002). MMP2, MMP3, and MMP 9 can both positively and, with the addition of MMP1, negatively regulate the activation of IL-1 (Ito et al, 1996; Schönbeck et al, 1998). The monocyte chemoattractant proteins, CCL2 (MCP-1), CCL7 (MCP-3), CCL8 (MCP-2), and CCL13 (MCP-4), are all regulated by MMPs. MMP2 cleaves CCL7 to an inactive form (MCQuibban et al, 2000), and MMP1 and MMP3 cleave the active forms of CCL2, CCL8, and CCL13 thereby reducing their chemoattractant activity (McQuibban et al, 2002). Our data add another level of complexity to the regulation of cytokines and chemokines by MMPS. We have shown that macrophage RET expression is tightly controlled and that activation via neurturin 


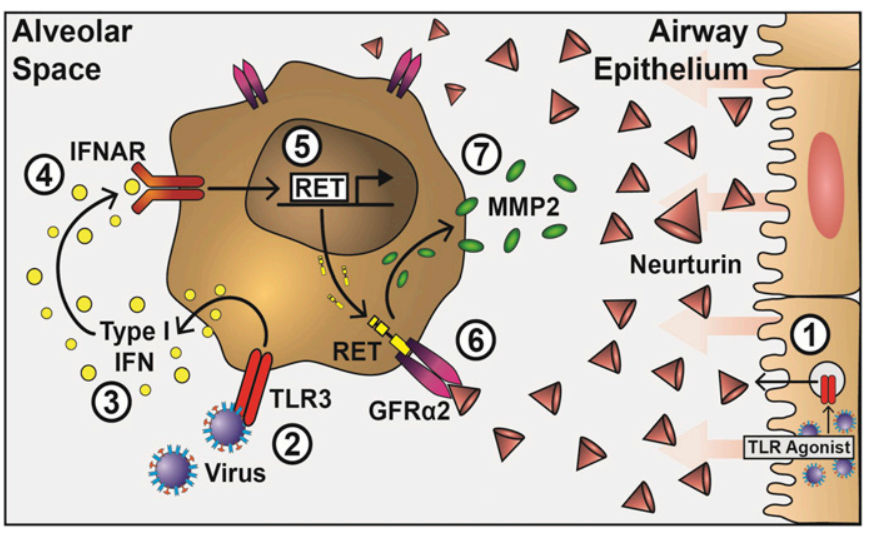

Figure 7. A novel role for the GDNF family on macrophages in respiratory viral infection.

TLR activation of airway epithelial cells enhances the production of NRTN, which binds to constitutively expressed GFR $\alpha 2$ on the surface of lung macrophages (1). Viral TLR activation on lung macrophages (2) triggers the release of IFN $\beta$ (3), which acts in an autocrine manner and binds to the IFN $\alpha / \beta$ receptor, IFNAR (4), to stimulate the production of RET at the MRNA and protein level (5). RET translocates to the cytoplasm and binds to GFR $\alpha 2$ (6), stimulating the production of MMP-2 (7) and dampening the pro-inflammatory cytokine response.

enhances MMP2 production and decreases MMP3 production in TLR3-activated lung macrophages. This may promote the release of active TGF $\beta$ and reduce the chemotactic potential of CCL7 to attract monocytes to the site of infection. However, with the crossover in cytokine and chemokine regulation by MMP2 and MMP3, it remains unclear how the effect of NRTN on the production of MMP2 and MMP3 by macrophages influences the inflammatory response to an infection in vivo.

Our knowledge of the roles of individual MMPs is still limited; however, several studies have implicated specific MMPs in respiratory disease. MMP2 has beneficial effects in a mouse model of asthma, where this MMP facilitates the resolution of allergic inflammation by allowing cells to egress to the lung (Corry et al, 2004). On the other hand, in the absence of MMP2 and/or MMP9, specific chemotactic gradients are disrupted and cause retention of cells in the lung parenchyma and inhibition of their exit via the airways (Haas \& Madri, 1999; Corry et al, 2002; Li et al, 2002; McGuire et al, 2003; Parks, 2003). Conversely, MMP3 has a detrimental role in mouse models of acute lung injury and pulmonary fibrosis, with MMP3-deficient mice exhibiting less severe lung injury and protection from bleomycin-induced fibrosis (Warner et al, 2001; Yamashita et al, 2011). Although further studies are required to elucidate the roles of MMPs in respiratory viral infections, it has been shown in a mouse model of severe influenza infection (IAV) that $\mathrm{MMPO}^{-/-}$mice exhibited increased survival and were protected from IAV-induced lung injury (Rojas-Quintero et al, 2018). This suggests that a reduction in MMP9 expression would be beneficial in host defence against respiratory viral infections. Interestingly, induction of MMP9 expression in macrophages of IAV-infected mice has been shown to be via the TLR7 pathway (Lee et al, 2017). This may explain why we did not observe an effect of NRTN on MMP9 expression in TLR3-activated macrophages. Although our this study is limited to in vitro experiments, our data suggest that in vivo the
GDNF family, through the regulation of MMPs, could affect the activity of cytokines and chemokines, influencing the cells that infiltrate the airways in response to a viral infection.

When investigating MMP expression at the mRNA and protein levels in our system, we noted some discrepancies, which highlights the need to validate expression at both molecular levels. We observed enhanced MMP2 at the mRNA level in IFN $\beta$-stimulated macrophages by NRTN; however, NRTN with polyl:C stimulation, but not IFN $\beta$ stimulation, enhanced MMP2 protein expression. It is not clear why we see this difference but suggests that other factors produced by TLR3 stimulation may be required for the alteration in MMP expression at the protein level induced by NRTN, which are not produced by IFN $\beta$ stimulation alone. In addition, MMP9 release from lung macrophages was reduced by IFN $\beta$ at the protein level; however, no differences were observed at the mRNA level. The disparity in mRNA and protein levels observed may be due to the different time points analysed or suggests that IFN $\beta$ has posttranslational effects on MMP9.

The GDNF family are members of the wider TGF $\beta$ superfamily (Airaksinen \& Saarma, 2002) and as such studies have investigated their anti-inflammatory functions. GFLs modulate T helper 2 (Th2) cells by decreasing IL-10 production in a RET-dependent manner (Almeida et al, 2014), NRTN knockout mice develop exaggerated inflammation to allergens (Mauffray et al, 2015) and addition of GDNF or NRTN to activated PBMCS reduces TNF protein (Vargas-Leal et al, 2005). In corroboration, our data demonstrates that in the setting of a viral infection, NRTN dampens the release of proinflammatory cytokines from human lung-resident macrophages. Overall, the outcome of GFR $\alpha 2$-NRTN-RET signalling in immune cells appears to limit excessive inflammation and drive inflammatory resolution.

Our data suggest that the GDNF family may be important factors to investigate in airway disease. We observed enhanced GFR $\alpha 2$ and MMP2 expression in lung macrophages from current smokers. Whether this impacts on the development of COPD, or exacerbations of the disease, remains to be elucidated. The glial cell line derived neurotrophic factor family were first characterised as neuronal growth factors involved in the development of the nervous system, in particular the enteric nervous system (Airaksinen \& Saarma, 2002). RET activation has not been directly linked to MMPS in nervous system formation; however, MMP2 is involved in the migration and network formation of enteric neural crest-derived cells (Anderson, 2010). The production of matrix proteins via RET activation has been better characterised in the context of cancer (Mulligan, 2018). Gain-of-function mutations in RET are associated with familial neuroendocrine tumours and medullary thyroid cancers (Jhiang, 2000). Deletion of RET in thyroid carcinomas has been shown to reduce the production of MMP2 and MMP9 (Lian et al, 2017). However, RET expression by immune cells in cancer has, to the best of our knowledge, not been previously assessed. MMPs are known to alter the microenvironment to aid cancer progression and metastases (Kessenbrock et al, 2010). Our data suggest that RET could be up-regulated in tumour macrophages, thereby limiting inflammation and enhancing MMP2 production within the tumour microenvironment. RET inhibition may therefore be an attractive therapeutic target in cancer as an immune modulator irrespective of the presence of RET-activating mutations. 
All epithelial surfaces have a dense network of nociceptors that enable them to sense noxious substances, cytokines, and pathogens (via pathogen-associated molecular patterns). In turn, neuronal factors released from peripheral neurons influence local cell recruitment, their activation and ultimately the profile of the immune response (for a review, see Talbot et al [2016]). This integrated system provides a rapid response to threat, which if reliant on the immune system alone, could take days to mobilize. Although NRTN redirected macrophage activity without the presence of neurons, in vivo we have not ruled out that epithelial-derived NRTN may influence local sensory neurons or that NRTN could be produced by other cell types, such as glial cells that have now been described in the lung (Suarez-Mier \& Buckwalter, 2015). The data suggest that epithelial cells may be able to communicate to neurons the type of threat involved and that neurons in turn may direct an appropriate response.

The alteration in cytokine and matrix protein production by the GFR $\alpha 2-R E T-N R T N$ complex that we describe provides many avenues for therapeutic modulation if the goal is to modulate specific MMP activity or inflammatory cytokine responses from macrophages. This may have the advantage of releasing the inflammatory potential of airway macrophages so that they are quicker at quelling an infectious agent. Further studies investigating the GDNF family in vivo may also elucidate the roles of specific MMPs and determine whether this is actually detrimental, or beneficial for resolution of inflammation.

\section{Materials and Methods}

\section{Study participants}

Regions of healthy marginal tissue ( $>6 \mathrm{~cm}$ from the cancer) were identified and dissected by a histopathologist under auspices of the Manchester Allergy, Respiratory and Thoracic Surgery (ManARTS) Biobank at the University Hospital of South Manchester. Ethical approval was granted by the National Research Ethics Service Committee (ref; 15/NW/0409). Participants with a forced expiratory volume in $1 \mathrm{~s} /$ forced vital capacity $\left(\mathrm{FEV}_{1} / \mathrm{FVC}\right)$ of $\geq 0.70$ with no other underlying respiratory disease were categorised as "healthy." Participants with COPD were defined by physician diagnosis and exhibited an $\mathrm{FEV}_{1} / \mathrm{FVC}<0.70$. Participants were also categorised based on smoking status and demographics as detailed in Table S1. Human lung macrophages from "healthy" nonsmokers were used for experiments unless otherwise stated. Lung tumour samples were collected from the Manchester Cancer Research Centre Biobank under the Manchester Cancer Research Centre Biobank Research Tissue Bank Ethics (ref; 18/NW/0092). All patients provided written consent for participation in the studies.

\section{Isolation of airway macrophages from human lung resection samples}

Sterile PBS was flushed through resected lung tissue using a 26 G needle and syringe until the liquid ran clear as described previously (Dewhurst et al, 2017). Cells were layered onto Ficoll-paque (GE Healthcare) the leukocyte cell layer collected, washed in sterile PBS and counted using trypan blue and a haemocytometer. Cells were plated in complete RPMI media (RPMI 1640, 10\% FCS, $100 \mathrm{U} / \mathrm{ml}$ penicillin, and $100 \mu \mathrm{g} / \mathrm{ml}$ streptomycin [all from Sigma-Aldrich]) and incubated for $1 \mathrm{~h}$ at $37^{\circ} \mathrm{C}$ to allow macrophages to adhere. For RNA and protein extraction cells were plated at $5 \times 10^{5}$ cells $/ \mathrm{ml}$ in a 12- or 6-well plate, respectively. For imaging, cells were plated at 1.5 $\times 10^{5}$ cells $/ \mathrm{ml}$ on coverslips in a 24 -well plate. Cells were washed three times with sterile PBS, media replaced and stimulated with polyl:C $(10 \mu \mathrm{g} / \mathrm{ml}$ ) (InvivoGen), IFN $\alpha$, IFN $\beta$, IFNy or IFN $\lambda$ (all used at 20 $\mathrm{ng} / \mathrm{ml}$ ), or NRTN (100 $\mathrm{ng} / \mathrm{ml}$ ) (all from Peprotech) and incubated for $24 \mathrm{~h}$ at $37^{\circ} \mathrm{C}$ before further processing.

\section{Isolation of macrophages from tumour tissue and matching healthy margin tissue}

Lung and tumour tissue was finely chopped and enzymatically digested with Liberase TL $(0.125 \mathrm{mg} / \mathrm{ml}$; Sigma-Aldrich) and DNase $(150 \mathrm{U} / \mathrm{ml}$; Sigma-Aldrich) in HBSS (Sigma-Aldrich) in a shaking incubator at $37^{\circ} \mathrm{C}$ for $30 \mathrm{~min}$. Tissue was passed through a $70 \mu \mathrm{M}$ filter and the cell suspension centrifuged at $400 \mathrm{~g}$ for $5 \mathrm{~min}$. Cells were resuspended in sterile distilled water for 30 s to lyse red blood cells. Cells were centrifuged and washed with sterile PBS and counted using trypan blue and a haemocytometer. Cells were plated at $1.25 \times 10^{5}$ cells $/ \mathrm{ml}$ in a 24-well plate and incubated for $1 \mathrm{~h}$ at $37^{\circ} \mathrm{C}$ to allow macrophages to adhere. Cells were washed three times with sterile PBS and lysed in RLT buffer (QIAGEN) for RNA extraction.

\section{Isolation and culture of MDMs}

Leukocyte apheresis cones from healthy donors were provided by the national blood transfusion service, layered onto Ficoll-paque (GE Healthcare) and leukocyte cell layer collected. Cells were washed in sterile PBS and counted using trypan blue and a haemocytometer. PBMCs were incubated with anti-human CD14 magnetic beads (Miltenyi Biotec) and sterile MACS buffer (sterile PBS, 0.5\% BSA, 2 mM EDTA) and passed through an LS MACS separation column in a MidiMACS separator according to the manufacturer's instructions (Miltenyi Biotec) to obtain purified $\mathrm{CD}^{+} 4^{+}$ monocytes. $\mathrm{CD} 14^{+}$monocytes were plated at $0.75 \times 10^{6}$ cells $/ \mathrm{ml}$ in a 12-well plate for RNA isolation or a six-well plate for protein extraction and cultured in complete RPMI media with M-CSF (50 ng/ml) (Peprotech). Half of the media was replaced after $3 \mathrm{~d}$ without the addition of M-CSF. After 6 $d$, media was replaced and differentiated macrophages stimulated with LPS (100 ng/ml), polyl:C (10 $\mu \mathrm{g} / \mathrm{ml}), \mathrm{R} 848$ (100 ng/ml) (all from InvivoGen), IFNy, IL-4, IL-10, IL-13, IFN $\alpha$, IFN $\beta$, or IFN $\lambda$ (all $20 \mathrm{ng} / \mathrm{ml}$ and from Peprotech) and incubated for $24 \mathrm{~h}$ at $37^{\circ} \mathrm{C}$ before further processing.

\section{Mouse model of influenza virus infection}

8- to 12-wk-old C57BL/6 mice (Harlan Olac Ltd) were kept in specific pathogen-free conditions at Bio Safety Level 2 with a controlled temperature $\left(21^{\circ} \mathrm{C} \pm 1^{\circ} \mathrm{C}\right)$, humidity $(55 \% \pm 10 \%)$, and a 12 -h light/dark cycle, with food and water ad libitum. All animal procedures were approved by the Home Office UK and by the University of Manchester Animal Welfare and Ethical Review Body, and conformed to the requirements of the UK Animals (Scientific Procedures) Act, 1986. Mice were lightly anaesthetised with isofluorane and infected intranasally with 7.5 plaque forming units of influenza A virus, Puerto Rico/8/ 
34(PR8), H1N1. Mice were euthanized by intraperitoneal injection of 3 mg pentobarbitone at specific time points post-infection. A $21 \mathrm{G}$ needle attached to a $0.2-\mathrm{mm}$ catheter tube was inserted into the mouse trachea and $3 \times 1 \mathrm{ml}$ of HBSS containing 0.05 M EDTA (Sigma-Aldrich) was flushed into the lungs to harvest BAL fluid and macrophages as previously described (Snelgrove et al, 2008).

\section{Isolation and culture of BMDMs}

Hind limbs were removed and the bone stripped of skin and muscle. The tips of the femur and tibia were cut and bone marrow flushed out with sterile PBS. Cells were centrifuged at $500 \mathrm{~g}$ for 5 min, supernatant discarded and the pellet resuspended in $3 \mathrm{ml}$ of red blood cell lysis buffer (Sigma-Aldrich) for $3 \mathrm{~min}$. After centrifugation, cells were washed in sterile PBS and resuspended in complete RPMI media with $20 \%$ FCS (Gibco) supplemented with GMCSF $(20 \mathrm{ng} / \mathrm{ml})$ or M-CSF $(20 \mathrm{ng} / \mathrm{ml}$ ) (both Peprotech) and cultured for $3 \mathrm{~d}$ at $37^{\circ} \mathrm{C}$. Media was replaced with complete RPMI media containing $10 \%$ FCS and cells further cultured for 4-7 d until confluent. Cells were lysed in RLT buffer and stored at $-80^{\circ} \mathrm{C}$ until RNA extraction.

\section{Cell lines}

THP-1 cells were cultured in complete RPMI media and plated at $5 \times$ $10^{5}$ cells $/ \mathrm{ml}$ in a six-well plate or at $2 \times 10^{5}$ cells $/ \mathrm{ml}$ on fibronectin coated coverslips in a 24-well plate for imaging. THP-1 cells were treated with $25 \mathrm{nM}$ phorbol 12-myristate 13-acetate (PMA) (SigmaAldrich) to induce differentiation into macrophages. After $48 \mathrm{~h}$, fresh complete RPMI medium was added to the cells and the plate incubated at $37^{\circ} \mathrm{C}$ overnight before stimulation. The medium was replaced and THP-1 cells were stimulated with IFN $\beta(20 \mathrm{ng} / \mathrm{ml})$, NRTN (100 ng/ml) (both from Peprotech), and/or AD80 (Selleckchem) and incubated for $24 \mathrm{~h}$ at $37^{\circ} \mathrm{C}$ before further processing. A549 cells were plated at $0.75 \times 10^{5}$ cells $/ \mathrm{ml}$ in a 12 -well plate in complete DMEM medium and incubated at $37^{\circ} \mathrm{C}$ overnight before stimulation. A549 cells were stimulated with polyl:C $(10 \mu \mathrm{g} / \mathrm{ml})$, LPS $(100 \mathrm{ng} / \mathrm{ml}$ ), R848 (100 ng/ml) (all InvivoGen), or IFN $\alpha$ or IFN $\beta$ (both $20 \mathrm{ng} / \mathrm{ml}$ and from Peprotech) and incubated for $24 \mathrm{~h}$ at $37^{\circ} \mathrm{C}$ before further processing.

\section{RNA extraction and qPCR}

RNA was isolated using the RNeasy micro kit according to the manufacturer's instructions (QIAGEN) and total RNA was quantified using a NanoDrop spectrophotometer (Thermo Fisher Scientific). Reverse transcription of equivalent amounts of RNA was carried out using the High-Capacity RNA-to-cDNA kit according to the manufacturer's instructions (Applied Biosystems). qPCR reactions were performed using TaqMan Fast Universal PCR master mix and predesigned Taqman expression assays (both from Life Technologies) or SybrGreen master mix (Applied Biosystems) on a Quantstudio 12k flex PCR system (Life Technologies). The $\mathrm{RT}^{2}$ Profiler qPCR array for mouse neurotrophins and receptors was carried out according to the manufacturer's instructions. $1 \mu \mathrm{g}$ of RNA from each sample was reverse transcribed using the RT2 First Strand Kit (QIAGEN) and qPCR reactions were performed using RT2 SybrGreen Rox qPCR
Master Mix. Data were analysed using the SABiosciences RT2 Profiler qPCR Array Data Analysis version 3.5. The GeneQuery Human Macrophage Cell Biology qPCR Array Kit was carried out according to the manufacturer's instructions. 250 ng CDNA was used in each well of the 96-well plate provided. Relative mRNA expression was calculated based on the $\triangle \triangle C T$ method (Livak \& Schmittgen, 2001) using QuantStudio 12K Flex Software v1.1.1 (Life Technologies).

The average mRNA expressions of the housekeeping genes RN18s and Hprt were used to calculate relative mRNA levels in mouse BMDMs and mouse alveolar macrophages. The mRNA expression of RPLPO was used to calculate relative mRNA levels in human monocytes, MDMs, BEAS-2B cells, A549 cells, THP-1 cells, and human lung, tumour, and sputum macrophages. RET9 was detected using the following primer pair: forward primer - 5'TCCCTTCCACATGGATTG-3'; reverse primer - 5'-ATCACAGAGAGGAAGGATAGT-3' and RET 51 was detected using the following primer pair: forward primer - 5'-CTCCCTTCCACATGGATTG-3'; reverse primer - 5'-TCAGCTCTCGTGAGTGGT-3'. Gene expression was normalised to the housekeeping gene GAPDH using the following primer pair: forward Primer, 5'-GAAGGTGAAGGTCGGAGT-3', reverse Primer, 5'-CATGGGTGGAATCATATTGGAA-3'.

\section{Protein extraction and Western blot analysis}

Human lung macrophages, MDMs and THP-1 macrophages were lysed in RIPA buffer (50 mM Tris-HCL [pH 7.4], 1\% NP-40, 0.25\% Sodium Deoxycholate, $150 \mathrm{mM} \mathrm{NaCl}$, and $1 \mathrm{mM}$ EDTA) with protease inhibitors (Protease Inhibitor Cocktail; Sigma-Aldrich). Protein concentrations were determined using a BCA Protein Assay Kit (Thermo Fisher Scientific). Equivalent amounts of protein $(50 \mu \mathrm{g})$ were added to $4 \times$ Laemmli sample buffer (2\% SDS, $20 \%$ glycerol, $0.2 \%$ bromophenol blue, $1 \mathrm{M}$ Tris- $\mathrm{HCl}$ [pH 6.8]). To detect RET in MDMs, $4 \%$ SDS in $1 \times$ laemmli sample buffer was used. Samples were loaded into 4-20\% mini-Protean TGX precast gels (Bio-Rad) and resolved by electrophoresis and transferred to nitrocellulose membranes (Bio-Rad) using a semi-dry Trans-Blot turbo transfer system (Bio-Rad). The membrane was blocked with 5\% milk (SigmaAldrich) and $0.1 \%$ Tween 20 (Sigma-Aldrich) in PBS for $1 \mathrm{~h}$ at room temperature and incubated overnight at $4^{\circ} \mathrm{C}$ with antibodies for GFR 22 (1:500; R\&D Systems), RET, MMP1, MMP2, MMP3, and MMP9 and pro-MMP9 (all used at 1:1,000; Cell Signalling Technology). Membranes were washed three times with $0.1 \%$ Tween 20 in PBS for 10 min and anti-rabbit HRP-conjugated secondary antibody (1:3,000; Dako) diluted in 5\% milk and $0.1 \%$ Tween 20 in PBS was added and incubated for $1 \mathrm{~h}$ at room temperature on an orbital shaker. $\beta$-actin-peroxidase (1:10,000; Sigma-Aldrich) was used as the housekeeping control. The membranes were developed using a Clarity Western ECL Substrate (Bio-Rad) and visualised with a ChemiDoc MP Imaging System (Bio-Rad).

\section{Immunocytochemistry and immunofluorescence}

Cells were fixed in 4\% paraformaldehyde for $20 \mathrm{~min}$, washed in PBS, and lung macrophages incubated in 10\% donkey serum in PBS and THP-1 macrophages incubated in 5\% goat serum and $0.3 \%$ Triton $\mathrm{X}-100$ in PBS to for $1 \mathrm{~h}$ at room temperature to block non-specific binding. Blocking buffer was removed and wells incubated with 
GFR 22 ( $5 \mu \mathrm{g} / \mathrm{ml}$; normal goat IgG isotype control; R\&D Systems) or RET $(2 \mu \mathrm{g} / \mathrm{ml}$; rabbit mAb IgG XP isotype control; Cell Signalling Technology) in PBS containing 1\% BSA $1 \%$ donkey serum or $1 \%$ BSA and $0.3 \%$ Triton $x-100$, respectively, overnight at $4^{\circ} \mathrm{C}$. Wells were washed three times with PBS and lung macrophages incubated with donkey antigoat IgG AF647 secondary antibody ( 1 $\mu \mathrm{g} / \mathrm{ml}$; Invitrogen) and THP-1 macrophages incubated with goat anti-rabbit IgG AF647 secondary antibody (1:1,000; Cell Signalling Technology) for $1 \mathrm{~h}$ at room temperature. Wells were washed three times with PBS and coverslips mounted onto slides using Prolong Gold Antifade reagent with DAPI overnight at room temperature in the dark. Images were collected on a Zeiss Axioimager.D2 upright microscope using a 20×/0.5 EC Plan-neofluar objective and captured using a Coolsnap HQ2 camera (Photometrics) through Micromanager software v1.4.23. Specific band pass filter sets for DAPI and Cy5 were used to prevent bleed through from one channel to the next. Images were then processed and analysed using Fiji ImageJ (http://imagej.net/Fiji/ Downloads).

\section{ELISAs}

IL-6, TNF $\alpha$, IL-12p40, IL-10 (all DuoSet; R\&D Systems), mouse NRTN (Stratech), and human NRTN (Universal Biologicals) were measured in supernatants, cell lysates, or BAL fluid by enzyme-linked immunosorbent assay (ELISA) according to the manufacturer's instructions.

\section{Gelatin degradation assay}

Matrix degradation by primary lung macrophages was measured using the QCM Gelatin Invadopodia Assay (EMD Millipore) according to the manufacturer's instructions. Lung macrophages were plated at $1.5 \times 10^{5}$ in Nunc Labtek 8-well chamber slides (Thermo Fisher Scientific). Cell induced degradation of fluorescent gelatin was quantified as either the percent of degradation area per cell or the percentage of degradation area per total cell area. Data are displayed as a relative percentage normalised to poly(I:C), with poly(I:C) set to $100 \%$. Analysis was performed according to manufactures instructions using Fiji ImageJ (http://imagej.net/Fiji/Downloads). DAPI and phalloidin signal was thresholded for high intensities, and then analysed as particles to provide a cell (nuclear) count or measurement of cell area. For quantification of the area of degradation Cy3-gelatin signal was thresholded for low intensities, then analysed as particles. Images were obtained using a Leica DM IL LED inverted microscope using a 4×/0.1 Hi-Plan objective and captured using a Leica DFC3000 G camera. Specific band pass filter sets for DAPI, FITC and Texas Red were used to prevent bleed through from one channel to the next.

\section{Statistics}

GraphPad Prism version 7 was used for all statistical analysis. For multiple dataset analysis of parametric data, ANOVA with Tukey's correction was applied. For multiple dataset analysis of non-parametric data, a Kruskal-Wallis test with Dunn's multiple comparisons test was applied. To compare two datasets, an unpaired or paired $t$ test was applied. Data are presented as the mean \pm SD. $P$-values $<0.05$ were considered significant $\left({ }^{\star} P<0.05,{ }^{\star *} P<0.01\right.$, $\left.{ }^{\star \star *} P<0.001\right)$.

\section{Supplementary Information}

Supplementary Information is available at https://doi.org/10.26508/lsa 202000780.

\section{Acknowledgements}

T Hussell is supported by an investigator award from the Wellcome Trust $(202865 / Z / 16 / Z)$. This research was also supported by a pre-competitive open innovation award from AstraZeneca and GlaxoSmithKline that formed the Manchester Collaborative Centre for Inflammation Research. We acknowledge the Manchester Allergy, Respiratory and Thoracic Surgery Biobank for supporting this project. The Bioimaging Facility microscopes used in this study were purchased with grants from Biotechnology and Biological Sciences Research Council (BBSRC), Wellcome Trust, and the University of Manchester Strategic Fund. We specially thank Peter March, Roger Meadows, and Steven Marsden for their help with the microscopy.

\section{Author Contributions}

E Connolly: formal analysis, validation, investigation, visualization, methodology, and writing-original draft.

DJ Morgan: formal analysis, investigation, methodology, and writing-review and editing.

M Franklin: formal analysis and investigation.

A Simpson: resources.

R Shah: resources.

OJ Brand: formal analysis and investigation.

CP Jagger: investigation and writing-review and editing.

J Casulli: visualization.

K Mohamed: investigation.

AM Grabiec: conceptualization, supervision, and methodology.

$T$ Hussell: conceptualization, supervision, funding acquisition, writing-original draft, and project administration.

\section{Conflict of Interest Statement}

The authors declare that they have no conflict of interest.

\section{References}

Airaksinen MS, Saarma M (2002) The GDNF family: Signalling, biological functions and therapeutic value. Nat Rev Neurosci 3: 383-394. doi:10.1038/nrn812

Almeida AR, Fonseca-Pereira D, Arroz-Madeira S, Ribeiro H, Labao-Almeida C, Veiga-Fernandes H (2014) The neurotrophic factor receptor RET regulates IL-10 production by in vitro polarised T helper 2 cells. Eur J Immunol 44: 3605-3613. doi:10.1002/eji.201344422

Anderson RB (2010) Matrix metalloproteinase-2 is involved in the migration and network formation of enteric neural crest-derived cells. Int I Dev Biol 54: 63-69. doi:10.1387/ijdb.082667ra

Artis D, Spits H (2015) The biology of innate lymphoid cells. Nature 517: 293-301. doi:10.1038/nature14189

Asai M, Kato M, Asai N, Iwashita T, Murakami H, Kawai K, Nakashima I, Takahashi M (1999) Differential regulation of MMP-9 and TIMP-2 expression in malignant melanoma developed in metallothionein/ 
RET transgenic mice. Jpn J Cancer Res 90: 86-92. doi:10.1111/j.13497006.1999.tb00670.x

Barnes PJ (2019) Small airway fibrosis in COPD. Int J Biochem Cell Biol 116: 105598. doi:10.1016/j.biocel.2019.105598

Beeh KM, Beier J, Kornmann O, Buhl R (2003) Sputum matrix metalloproteinase-9, tissue inhibitor of metalloprotinease-1, and their molar ratio in patients with chronic obstructive pulmonary disease, idiopathic pulmonary fibrosis and healthy subjects. Respir Med 97: 634-639. doi:10.1053/rmed.2003.1493

Belvisi MG, Bottomley KM (2003) The role of matrix metalloproteinases (MMPs) in the pathophysiology of chronic obstructive pulmonary disease (COPD): A therapeutic role for inhibitors of MMPs? Inflamm Res 52: 95-100. doi:10.1007/s000110300020

Chesne J, Cardoso V, Veiga-Fernandes H (2019) Neuro-immune regulation of mucosal physiology. Mucosal Immunol 12: 10-20. doi:10.1038/s41385018-0063-y

Clark K, Peggie M, Plater L, Sorcek RJ, Young ER, Madwed JB, Hough J, Mclver EG, Cohen P (2011) Novel cross-talk within the IKK family controls innate immunity. Biochem J 434: 93-104. doi:10.1042/bj20101701

Corry DB, Kiss A, Song LZ, Song L, Xu J, Lee SH, Werb Z, Kheradmand F (2004) Overlapping and independent contributions of MMP2 and MMP9 to lung allergic inflammatory cell egression through decreased CC chemokines. FASEB J 18: 995-997. doi:10.1096/fj.03-1412fje

Corry DB, Rishi K, Kanellis J, Kiss A, Song Lz LZ, Xu J, Feng L, Werb Z, Kheradmand F (2002) Decreased allergic lung inflammatory cell egression and increased susceptibility to asphyxiation in MMP2deficiency. Nat Immunol 3: 347-353. doi:10.1038/ni773

Dallas SL, Rosser JL, Mundy GR, Bonewald LF (2002) Proteolysis of latent transforming growth factor-beta (TGF-beta)-binding protein-1 by osteoclasts. A cellular mechanism for release of TGF-beta from bone matrix. J Biol Chem 277: 21352-21360. doi:10.1074/jbc.m111663200

Dewhurst JA, Lea S, Hardaker E, Dungwa JV, Ravi AK, Singh D (2017) Characterisation of lung macrophage subpopulations in COPD patients and controls. Sci Rep 7: 7143. doi:10.1038/s41598-017-07101-2

Fonseca-Pereira D, Arroz-Madeira S, Rodrigues-Campos M, Barbosa IA, Domingues RG, Bento T, Almeida AR, Ribeiro H, Potocnik AJ, Enomoto $\mathrm{H}$, et al (2014) The neurotrophic factor receptor RET drives haematopoietic stem cell survival and function. Nature 514: 98-101. doi:10.1038/nature13498

Garcia-Garcia A, Korn C, Garcia-Fernandez M, Domingues O, Villadiego J, Martin-Perez D, Isern J, Bejarano-Garcia JA, Zimmer J, Perez-Simon JA, et al (2019) Dual cholinergic signals regulate daily migration of hematopoietic stem cells and leukocytes. Blood 133: 224-236. doi:10.1182/blood-2018-08-867648

Gearing AJ, Beckett P, Christodoulou M, Churchill M, Clements J, Davidson AH, Drummond AH, Galloway WA, Gilbert R, Gordon JL, et al (1994) Processing of tumour necrosis factor-alpha precursor by metalloproteinases. Nature 370: 555-557. doi:10.1038/370555a0

Goritzka M, Makris S, Kausar F, Durant LR, Pereira C, Kumagai Y, Culley FJ, Mack M, Akira S, Johansson C (2015) Alveolar macrophage-derived type I interferons orchestrate innate immunity to RSV through recruitment of antiviral monocytes. J Exp Med 212: 699-714. doi:10.1084/ jem.20140825

Haas TL, Madri JA (1999) Extracellular matrix-driven matrix metalloproteinase production in endothelial cells: Implications for angiogenesis. Trends Cardiovasc Med 9: 70-77. doi:10.1016/s1050-1738(99)00014-6

Hendrix AY, Kheradmand $F$ (2017) The role of matrix metalloproteinases in development, repair, and destruction of the lungs. Prog Mol Biol Transl Sci 148: 1-29. doi:10.1016/bs.pmbts.2017.04.004

Hussell T, Bell TJ (2014) Alveolar macrophages: Plasticity in a tissue-specific context. Nat Rev Immunol 14: 81-93. doi:10.1038/nri3600
Ibiza S, Garcia-Cassani B, Ribeiro H, Carvalho T, Almeida L, Marques R, Misic AM, Bartow-McKenney C, Larson DM, Pavan WJ, et al (2016) Glial-cellderived neuroregulators control type 3 innate lymphoid cells and gut defence. Nature 535: 440-443. doi:10.1038/nature18644

Ito A, Mukaiyama A, Itoh Y, Nagase H, Thogersen IB, Enghild JJ, Sasaguri Y, Mori Y (1996) Degradation of interleukin 1beta by matrix metalloproteinases. J Biol Chem 271: 14657-14660. doi:10.1074/ jbc.271.25.14657

Ivashkiv LB, Donlin LT (2014) Regulation of type I interferon responses. Nat Rev Immunol 14: 36-49. doi:10.1038/nri3581

Jensen CT, Ahsberg J, Sommarin MNE, Strid T, Somasundaram R, Okuyama K, Ungerback J, Kupari J, Airaksinen MS, Lang S, et al (2018) Dissection of progenitor compartments resolves developmental trajectories in Blymphopoiesis. J Exp Med 215: 1947-1963. doi:10.1084/jem.20171384

Jhiang SM (2000) The RET proto-oncogene in human cancers. Oncogene 19 5590-5597. doi:10.1038/sj.onc.1203857

Kang J, Perry JK, Pandey V, Fielder GC, Mei B, Qian PX, Wu ZS, Zhu T, Liu DX, Lobie PE (2009) Artemin is oncogenic for human mammary carcinoma cells. Oncogene 28: 2034-2045. doi:10.1038/onc.2009.66

Karsdal MA, Larsen L, Engsig MT, Lou H, Ferreras M, Lochter A, Delaissé JM, Foged NT (2002) Matrix metalloproteinase-dependent activation of latent transforming growth factor-beta controls the conversion of osteoblasts into osteocytes by blocking osteoblast apoptosis. J Biol Chem 277: 44061-44067. doi:10.1074/jbc.m207205200

Kato M, Takahashi M, Akhand AA, Liu W, Dai Y, Shimizu S, Iwamoto T, Suzuki H, Nakashima I (1998) Transgenic mouse model for skin malignant melanoma. Oncogene 17: 1885-1888. doi:10.1038/sj.onc.1202077

Kessenbrock K, Plaks V, Werb Z (2010) Matrix metalloproteinases: Regulators of the tumor microenvironment. Cell 141: 52-67. doi:10.1016/ j.cell.2010.03.015

Lee YH, Huang JH, Chang TH, Yang HC, Wu-Hsieh BA (2017) Mucosa-associated lymphoid tissue lymphoma translocation protein 1 positively modulates matrix metalloproteinase-9 production in alveolar macrophages upon toll-like receptor 7 signaling and influenza virus infection. Front Immunol 8: 1177. doi:10.3389/fimmu.2017.01177

Lemmon MA, Schlessinger J (2010) Cell signaling by receptor tyrosine kinases Cell 141: 1117-1134. doi:10.1016/j.cell.2010.06.011

Li Q, Park PW, Wilson CL, Parks WC (2002) Matrilysin shedding of syndecan-1 regulates chemokine mobilization and transepithelial efflux of neutrophils in acute lung injury. Cell 111: 635-646. doi:10.1016/s00928674(02)01079-6

Lian EY, Maritan SM, Cockburn JG, Kasaian K, Crupi MJ, Hurlbut D, Jones SJ, Wiseman SM, Mulligan LM (2017) Differential roles of RET isoforms in medullary and papillary thyroid carcinomas. Endocr Relat Cancer 24: 53-69. doi:10.1530/erc-16-0393

Livak KJ, Schmittgen TD (2001) Analysis of relative gene expression data using real-time quantitative PCR and the 2(-Delta Delta C(T)) method. Methods 25: 402-408. doi:10.1006/meth.2001.1262

Loffek S, Schilling O, Franzke CW (2011) Series "matrix metalloproteinases in lung health and disease": Biological role of matrix metalloproteinases: A critical balance. Eur Respir J 38: 191-208. doi:10.1183/09031936.00146510

Maeda S, Dean DD, Gomez R, Schwartz Z, Boyan BD (2002) The first stage of transforming growth factor beta1 activation is release of the large latent complex from the extracellular matrix of growth plate chondrocytes by matrix vesicle stromelysin-1 (MMP-3). Calcif Tissue Int 70: 54-65. doi:10.1007/s002230010032

Matoba N, Akiyama M, Ishigaki K, Kanai M, Takahashi A, Momozawa Y, Ikegawa S, Ikeda M, Iwata N, Hirata M, et al (2019) GWAS of smoking behaviour in 165,436 Japanese people reveals seven new loci and shared genetic architecture. Nat Hum Behav 3: 471-477. doi:10.1038/s41562-019-0557-y 
Mauffray M, Domingues O, Hentges F, Zimmer J, Hanau D, Michel T (2015) Neurturin influences inflammatory responses and airway remodeling in different mouse asthma models. I Immunol 194: 1423-1433. doi:10.4049/jimmunol.1402496

McGuire JK, Li Q, Parks WC (2003) Matrilysin (matrix metalloproteinase-7) mediates E-cadherin ectodomain shedding in injured lung epithelium. Am J Pathol 162: 1831-1843. doi:10.1016/s0002-9440(10) 64318-0

McQuibban GA, Gong JH, Tam EM, McCulloch CA, Clark-Lewis I, Overall CM (2000) Inflammation dampened by gelatinase A cleavage of monocyte chemoattractant protein-3. Science 289: 1202-1206. doi:10.1126/ science.289.5482.1202

McQuibban GA, Gong JH, Wong JP, Wallace JL, Clark-Lewis I, Overall CM (2002) Matrix metalloproteinase processing of monocyte chemoattractant proteins generates CC chemokine receptor antagonists with antiinflammatory properties in vivo. Blood 100: 1160-1167. doi:10.1182/ blood.v100.4.1160.h81602001160_1160_1167

Mesa C Jr., Mirza M, Mitsutake N, Sartor M, Medvedovic M, Tomlinson C, Knauf JA, Weber GF, Fagin JA (2006) Conditional activation of RET/PTC3 and BRAFV600E in thyroid cells is associated with gene expression profiles that predict a preferential role of BRAF in extracellular matrix remodeling. Cancer Res 66: 6521-6529. doi:10.1158/0008-5472.can-060739

Mulligan LM (2018) GDNF and the RET receptor in cancer: New insights and therapeutic potential. Front Physiol 9: 1873. doi:10.3389/ fphys.2018.01873

Overall CM (2002) Molecular determinants of metalloproteinase substrate specificity: Matrix metalloproteinase substrate binding domains, modules, and exosites. Mol Biotechnol 22: 51-86. doi:10.1385/mb:22:1: 051

Parks WC (2003) Matrix metalloproteinases in lung repair. Eur Respir J Suppl 44: 36s-38s. doi:10.1183/09031936.03.00001203

Rauch I, Muller M, Decker T (2013) The regulation of inflammation by interferons and their STATs. JAKSTAT 2: e23820. doi:10.4161/jkst.23820

Rojas-Quintero J, Wang X, Tipper J, Burkett PR, Zuñiga J, Ashtekar AR, Polverino F, Rout A, Yambayev I, Hernández C, et al (2018) Matrix metalloproteinase-9 deficiency protects mice from severe influenza $A$ viral infection. JCl Insight 3: e99022. doi:10.1172/jci.insight.99022

Rusinova I, Forster S, Yu S, Kannan A, Masse M, Cumming H, Chapman R, Hertzog PJ (2013) Interferome v2.0: An updated database of annotated interferon-regulated genes. Nucleic Acids Res 41: D1040-D1046. doi:10.1093/nar/gks1215

Schneider C, Nobs SP, Kurrer M, Rehrauer H, Thiele C, Kopf M (2014) Induction of the nuclear receptor PPAR-gamma by the cytokine GM-CSF is critical for the differentiation of fetal monocytes into alveolar macrophages. Nat Immunol 15: 1026-1037. doi:10.1038/ni.3005
Schönbeck U, Mach F, Libby P (1998) Generation of biologically active IL-1 beta by matrix metalloproteinases: A novel caspase-1-independent pathway of IL-1 beta processing. I Immunol 161: 3340-3346.

Schuchardt A, D'Agati V, Larsson-Blomberg L, Costantini F, Pachnis V (1994) Defects in the kidney and enteric nervous system of mice lacking the tyrosine kinase receptor Ret. Nature 367: 380-383. doi:10.1038/ $367380 a 0$

Snelgrove RJ, Goulding J, Didierlaurent AM, Lyonga D, Vekaria S, Edwards L, Gwyer E, Sedgwick JD, Barclay AN, Hussell T (2008) A critical function for CD200 in lung immune homeostasis and the severity of influenza infection. Nat Immunol 9: 1074-1083. doi:10.1038/ni.1637

Sternlicht MD, Werb Z (2001) How matrix metalloproteinases regulate cell behavior. Annu Rev Cell Dev Biol 17: 463-516. doi:10.1146/ annurev.cellbio.17.1.463

Suarez-Mier GB, Buckwalter MS (2015) Glial fibrillary acidic proteinexpressing glia in the mouse lung. ASN Neuro 7: 1759091415601636. doi:10.1177/1759091415601636

Talbot S, Foster SL, Woolf CJ (2016) Neuroimmunity: Physiology and pathology. Annu Rev Immunol 34: 421-447. doi:10.1146/annurevimmunol-041015-055340

Vargas-Leal V, Bruno R, Derfuss T, Krumbholz M, Hohlfeld R, Meinl E (2005) Expression and function of glial cell line-derived neurotrophic factor family ligands and their receptors on human immune cells. I Immunol 175: 2301-2308. doi:10.4049/jimmunol.175.4.2301

Veiga-Fernandes H, Coles MC, Foster KE, Patel A, Williams A, Natarajan D, Barlow A, Pachnis V, Kioussis D (2007) Tyrosine kinase receptor RET is a key regulator of Peyer's patch organogenesis. Nature 446: 547-551. doi:10.1038/nature05597

Warner RL, Beltran L, Younkin EM, Lewis CS, Weiss SJ, Varani J, Johnson KJ (2001) Role of stromelysin 1 and gelatinase B in experimental acute lung injury. Am J Respir Cell Mol Biol 24: 537-544. doi:10.1165/ ajrcmb.24.5.4160

Wong KL, Tai JJ, Wong WC, Han H, Sem X, Yeap WH, Kourilsky P, Wong SC (2011) Gene expression profiling reveals the defining features of the classical, intermediate, and nonclassical human monocyte subsets. Blood 118: e16-e31. doi:10.1182/blood-2010-12-326355

Yamashita CM, Dolgonos L, Zemans RL, Young SK, Robertson J, Briones N, Suzuki T, Campbell MN, Gauldie J, Radisky DC, et al (2011) Matrix metalloproteinase 3 is a mediator of pulmonary fibrosis. Am J Pathol 179: 1733-1745. doi:10.1016/j.ajpath.2011.06.041

Yan N, Chen ZJ (2012) Intrinsic antiviral immunity. Nat Immunol 13: 214-222. doi:10.1038/ni.2229

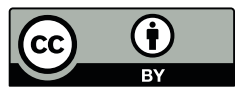

License: This article is available under a Creative Commons License (Attribution 4.0 International, as described at https://creativecommons.org/ licenses/by/4.0/). 